\title{
Literary Serial Killer Fiction: The Evolution of a Genre
}

\author{
By \\ Grant Cook \\ B.A. Canterbury University \\ B.A. Hons. Victoria University
}

A thesis submitted to Victoria University of Wellington

in fulfilment of the requirements of the degree of

Master of Arts in English Literature

Victoria University of Wellington

2017 


\begin{abstract}
This study examines the dynamics of post-war American serial killer fiction as it relates to social and literary contexts. In the context of history and development, this study considers the impact and origins of particular works and how they have influenced the stylistic and thematic evolution of a particular subgenre I have called literary serial killer fiction. Emphasis is placed on select narratives that directly (or indirectly) transform, challenge and critique the genre conventions in which they are written. Of interest is the evolution of general serial killer fiction as a postmodern phenomenon, in terms of its popularity with the reading public, and in line with the growth of media interest in representations of serial killers. I draw on literary theory (in particular, 'new historicism') to demonstrate that the appeal and tropes of serial killer fiction reflect sociopolitical interests indicative of the era from where they were produced, and to show how the subgenre of literary serial killer fiction can be categorized using its own particular set of defining features.

I examine these aspects in detail in relation to the following selection of fictional serialkiller narratives: Jim Thompson's The Killer Inside Me, James Ellroy's Killer on the Road, and Brett Easton Ellis's American Psycho. For brevity's sake, I have selected American narrative works that employ first-person narration and are transgressive in the way they focus on characters who defy convention and push boundaries, as do the narratives within larger genre traditions and protocols. In my view, these works are the purest examples of literary serial killer fiction in that they are characteristically unlike other examples that can easily be categorised under other literary genres.

The appeal and popularity of the genre, alongside the functional aspects of the trope, leads me to conclude that it is an ideal form to interact with popular cultural narratives, while also allowing subversive interplay between both real and fictional concerns. The appeal of the genre to those authors who usually write outside of it, particularly in regard to its transgressive and allegorical qualities, is also of particular interest to this study. Because of the hybrid nature of the genre and the ease with which the central trope of the fictional serial killer transcends genres, the resulting possibilities provide a transgressive outlet for authors who wish to test boundaries, in both a literary and an ontological sense, in regard to the commentary serial killer fiction allows on the state of contemporary American literature and society.
\end{abstract}




\section{Table of Contents}

INTRODUCTION:

LITERARY SERIAL KILLER FICTION - ORIGINS AND EVOLUTION 1.

- Towards a working definition of literary serial killer fiction .................

- Origins, development and critical reception ............................ 9.

- Postmodern influences ................................................ 16.

- The lineage of folklore, the Gothic and true crime narratives ............ 20.

- Characteristics of literary serial killer fiction ......................... 23.

CHAPTER ONE:

JIM THOMPSON'S THE KILLER INSIDE ME - PORTRAIT OF A SERIAL KILLER .......30.

CHAPTER TWO:

JAMES ELLROY'S KILLER ON THE ROAD - THE FIRST POST-MODERN SERIAL

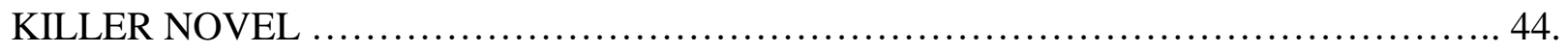

CHAPTER THREE:

BRETT EASTON ELLIS'S AMERICAN PSYCHO - SURFACES AND THE

COMMODIFICATION OF SERIAL MURDER

61.

CHAPTER FOUR: CONCLUSION

A WORKING DEFINITION OF LITERARY SERIAL KILLER FICTION

74.

WORKS CITED: 


\section{Introduction - Literary Serial Killer Fiction: Origins and Evolution}

\section{Towards a working definition of literary serial killer fiction}

This thesis seeks to clarify the classification and categorization of serial killer fiction and, more particularly, literary serial killer fiction. After outlining an approach to determine what constitutes serial killer fiction, I will use a range of exemplars to illustrate key aspects of what defines a work as literary serial killer fiction. More specifically, I show that there exists a stylistic criterion that distinguishes one type of serial killer fiction from another. Most fictional serial killer narratives commonly employ the serial killer as a plot device in a formulaic way and relegate the character to the secondary role of antagonist; these works can be classified as serial killer fiction within the crime fiction genre and associated subgenres (such as thriller, detective, mystery and noir). The other discernible branch of serial killer narratives are works that can be seen as more complex, in both style and content, and that counter the formulaic aspects of more

typical genre fiction. These works place the serial killer, usually in an allegorical fashion, as the focus of the narrative and are primarily concerned with the killer's point of view. It is these 
particular narratives that are the central concern of this study and are differentiated as literary serial killer fiction.

As paradoxical as it may seem, the serial killer is usually portrayed as an 'every man' figure - the average, ordinary human who hides a dark and deadly secret behind a normal countenance. Steven Egger, an authority on the subject of serial murder, suggests in his study, The Killers Among Us: An Examination of Serial Murder and its Investigation, that "serial murderers do not look like killers, nor does their appearance reflect an ultimate evil. Unfortunately, serial killers do not stand out ... as anything other than the average person" (47). He (for in the majority of cases the serial killer is male) could be your father, brother or uncle; moreover, it is precisely because of this familiarity which makes him such a terrifying embodiment of the human potential for evil. Despite the apparent commonality of the serial killer's outward appearance, in instances of serial killer fiction (particularly, literary serial killer fiction) consideration is given in most instances to the antithetical interior world of the killer. This inversion of normalcy is usually achieved by accentuating the abnormal and deviant psychological processes of the serial killer. The characterisation of the serial killer as both familiar and foreign, is common to most serial killer narratives but can also be seen as part of a larger myth-making cultural process specific to America, which creates anti-heroes out of American villains. Steven Egger observes that the:

United States has long made legends out of outlaws. American history is full of the folklore of killers, many of the so-called heroes of yesteryear, including the lawmen and gunslingers of the old West, would fit the modern definition of serial killer. The legends of Wyatt Earp, Billy the Kid and Butch Cassidy and the Sundance kid all contribute to this mystique. One of the key elements of the personality of the serial killer appears to be that he kills for an intrinsic motive, simply, he enjoys killing. Many of the "heroes" of the West displayed this trait. All forms of the media have contributed to this portrayal of serial killers as clever, daring, sexy, and elusive. (103)

The serial killer figure in both fact and fiction is permeated with this symbolic appeal (to American audiences) because of a combination of these elements. As Simpson suggests, "[t]he serial killer . . . achieves legendary status, largely through clever textual strategies that relocate the monstrous face behind the human one" (3). Genre fiction conceits, public interest, 'factual' narratives, and cultural concerns, continue to further the mythogenic construction of what has become a malleable narrative trope in the form of the serial killer. These influences typically 
position the serial killer as an allegorical representation of fear and danger. In Natural Born Celebrities: Serial Killers In American Culture, David Schmid suggests that the serial killer is "as quintessentially American a figure as the cowboy, and we should acknowledge this fact not least because the intrinsic Americanness of the serial killer has been a feature of writing about serial murder since at least the time of Jack the Ripper . . . In the words of a 1994 National Examiner headline: "Serial Killers Are As American As Apple Pie." (Natural Born Celebrities, 25). It is this cultural context that is the most relevant, in order to understand the allure and the ongoing popularity with American audiences of such narratives and why the genre continues to attract serious literary practitioners. Additionally, Schmid cites Philip Jenkins' assertion that American public interest reached a crescendo during the mid-1980s when various media and government agencies "worked together to produce a "serial killer panic,", heavily reliant on hyperbolic claims related to the growth and quantity of the distinctively 'American phenomenon' (15). While this suggests that public awareness and concern peaked during this period, it also reflects the basis for many of the fictional serial killer narratives produced before and after this time. In addition to classifying serial killer narratives in literary terms, the importance of truecrime reportage regarding the perpetuation of cultural interest in the topic of serial killers and the development of the genre of serial killer fiction, is central to this discussion. The significant influence of factual serial killer reportage is especially evident in the following (literary serial killer fiction) narratives, which are the subject of this analysis: Jim Thompson's The Killer Inside Me, James Ellroy's Killer On The Road, and Bret Easton Ellis's American Psycho.

Before classifying both serial killer fiction and literary serial killer fiction, the definition of and origin of the term 'serial killer' must be explained. In The Killers Among Us, Steven Egger traces the term back to the early 1980s when it was first used by Federal agencies to report on the 'wave' of serial murder and subsequent hysteria sweeping across America. David Schmid's examination of the 'celebrity criminal' in Natural Born Celebrities: Serial Killers in American Culture, situates the term 'serial murder' (as opposed to 'serial killer') and its first apparent appearance in criminological studies. ${ }^{1}$ Schmid suggests that the first instance can be

\footnotetext{
1. Schmid suggests that the term 'serial murder' and associated terminology first came to prominence on:

'... October 26, 1983, when the Justice Department held a news conference in Washington, D.C., to "disclose some of the findings from ... preliminary research into ... the problem of 'serial murders,' killings by such people as Jack the Ripper or the Boston Strangler.". . This news conference is important for two reasons. First, it marks the point when the concept of "serial murder"
} 
found in Grierson Dickson's 1958 study Murder by Numbers, in which he states that the term 'series-murder' is redundant, proposing instead that it should be replaced by the use of 'multicide' in criminological texts. Both terms ('series murder' and 'multicide') were overshadowed by later terminologies and definitions found in John Brophy's 1966 work, The Meaning of Murder. Brophy realized homicide of a serial nature, committed by one or more persons together, was a distinct phenomenon and that it warranted a more apt title. Dickson's earlier use of the term 'series murder' was appropriated by Brophy and subsequently used to "distinguish serial murder committed for gain from serial murder motivated by psychopathy" (71). Schmid goes on to point out the best known use of the term 'serial killer,' is attributed to the FBI agent Robert K Ressler, founder of the bureau's Vi-CAP (Violent Criminal Apprehension Program) and profiling unit. In Morton and Hilts's Serial Murder: Multidisciplinary Perspectives for Investigators, the Federal (legal) definition of the term is as follows: "serial killings' means a series of three or more killings . . . having common characteristics such as to suggest the reasonable possibility that the crimes were committed by the same actor or actors" (8).

More recently, Katherine Ramsland, a prominent true-crime author and professor of forensic psychology, recounts in a Psychology Today article how Harold Schechter (another renowned true crime author and serial-killer expert) discovered that the term 'serial killer' was first used in the 1930s in an account of the crimes of notorious serial murderer, Peter Kürten, by translator/author, Margaret Seaton Wagner in her book titled The Monster of Düsseldorf (1933). ${ }^{2}$ Thus the term 'serial killer' has gone through variations but seems to have maintained its currency as a noun. The Oxford English Dictionary offers the following definition that best serves my purpose in this thesis: "serial killer: a person who commits a series of murders, often with no apparent motive and typically following a characteristic, predictable behaviour pattern."

came to the attention of the public as a whole for the first time... Second, the news conference determined that the direction of future public policy and mass media discussions of serial murder would be favorable to the FBI's goals by defining the nature and scope of serial murder in highly specific and partial terms.' (77)

2. The book was an account of the crimes of notorious serial murderer, Peter Kürten. Schecter quotes from the book appears in the following Psychology Today article - https://www.psychologytoday.com/blog/shadow-boxing/201410/who-coined-serial-killer: Ernst August Ferdinand Gennat was director of the Berlin Criminal Police. He worked at developing a dedicated homicide squad, the Zentrale Mordinspektion, and by 1931, they were solving nearly 95\% of these crimes. Writers like Wagner who covered his work credited Gennat with suggesting the phrase, "serial killer." He used serienmörder in reference to the case of Peter Kürten, and Wagner translated this as 'series-murderer. 
Just as the factual serial killer has a set of prerequisite conditions that determine and define his character, so too does the fictional psychopathic serial killer.

Perhaps one of the more poignant observations of the psychopath, from both a cultural and literary perspective, can be found in author Norman Mailer's essay 'The White Negro.' Mailer's alignment of the 'hipster' with the psychopath, seeks to explain a subcultural movement in American cultural history (that is, the rise of the 'beats') which also parallels the rise of the serial killer phenomenon. The 'White Negro' particularly illustrates the prevalence of public knowledge about psychopathic personalities and the increased awareness of their function within American society. Mailer's essay not only delves into the apparent connection between 'hipsters' and a collective type of psychopathology, he also offers some striking interpretations of psychopathic personalities in general, which typify representations of fictional serial (sexually motivated) killers:

The psychopath murders - if he has the courage — out of the necessity to purge his violence, for if he cannot empty his hatred then he cannot love, his being is frozen with implacable self-hatred for his cowardice... At bottom, the drama of the psychopath is that he seeks love. Not love as the search for a mate, but love as the search for an orgasm more apocalyptic than the one which preceded it. Orgasm is his therapy — he knows at the seed of his being that good orgasm opens his possibilities and bad orgasm imprisons him. But in this search, the psychopath becomes an embodiment of the extreme contradictions of the society which formed his character, and the apocalyptic orgasm often remains as remote as the Holy Grail, for there are clusters and nests and ambushes of violence in his own necessities and in the imperatives and retaliations of the men and women among whom he lives his life, so that even as he drains his hatred in one act or another, so the conditions of his life create it anew in him until the drama of his movements bears a sardonic resemblance to the frog who climbed a few feet in the well only to drop back again.

(Dissent, 284)

This insight into the same era that produced the first notable works of American literary serial killer fiction, indicate that both factual and fictional narratives of that era were actively engaged in interpreting and understanding representations of the violent psychopath ala serial killer. While not the first text to include a serial murderer, I argue that Jim Thompson's pulp novel, The Killer Inside Me, was the first 'pure' example of contemporary serial killer fiction and the first example of literary serial killer fiction, in accordance with the defining characteristics outlined in this essay. Specific features of Thompson's novel differed radically from existing representations of multiple murder that sat comfortably within the crime fiction (including 
mystery and detective), horror, war and western genres. While these fiction categories included works that dealt with multiple murder, they were firmly entrenched in their respective conventional tropes and traditions. Thompson's novel differentiated itself by the use of firstperson narration, stream of consciousness and the inclusion of anti-authoritarian themes of paranoia, violence and psychological subterfuge. Of course, previous works of American literature had employed these techniques; including Moby Dick by Herman Melville (1851), The Adventures of Huckleberry Finn, by Mark Twain (1884), The Sound and the Fury by William Faulkner (1929), The Lady in the Lake by Raymond Chandler (1944), The Way Some People Die by Ross Macdonald (1951) and The Catcher in the Rye by J. D. Salinger (1951), to name a few.

Despite the availability of fictional narratives published before The Killer Inside Me (that employ the tropes and techniques listed above), few American authors had explicated the inner workings of the psychopath, especially from a first-person perspective. A handful of examples of American novels exist where multiple murder is represented (pre-1950) with a focus on the murderer, but from a more observational perspective than Thompson's expose of the serial killer from a first-person point of view. Some of these titles include Philip MacDonald's 'The Mystery of The Dead Police’ (1933) and Ellery Queen's 'Cat of Many Tails' (1949). These novels were not the only narratives to employ first person narration or focus on the psychopathology of the murderer; international examples include Fyodor Dostoyevsky's Crime and Punishment (1866), Jean-Paul Sartre's Nausea (1938), and Albert Camus's The Stranger (1942).

While these fictional antecedents possibly influenced and informed Thompson's narrative style, he differentiated himself as one of the first American authors to combine characteristic tropes of noir/crime fiction, with the more violent and lurid aspects of pulp fiction, contemporary psychoanalytical theory, and ironic social commentary with a focus on the serial killer. While these features do not, of themselves, have any necessary relationship with serial killing, the effect of combining them in a narrative that so powerfully characterised the serial killer as a particular kind of American hybrid personality, made Thompson's novel a template for many subsequent treatments of the serial killer. Effectively, he had produced a culturally relevant and unique work in The Killer Inside Me (1952) that signalled, and influenced, the establishment of the serial killer as a distinct trope within genre fiction. Other noteworthy examples of serial killer fiction that were published in the 1950s include The Night of the Hunter by Davis Grubb (1953), The Bad Seed by William March (1954), The Talented Mr. Ripley by Patricia Highsmith (1955), 
and, most notably, Psycho by Robert Bloch (1959). It is interesting to note that Thompson's Killer Inside Me and Bloch's Psycho bookend the decade with two distinct strains of serial killer fiction; Thompson's novel being the first example of what I term literary serial killer fiction and Bloch's exemplifying that which is the more general serial killer fiction.

Most of the narratives mentioned above have recourse to factual events and crimes of that era. Bloch's Psycho, for example, was inspired by the grisly serial murders of American serial killer Edward Gein. In The Serial Killer Files, Harold Schechter describes how, similar to the character of Norman Bates, Gein was perversely fixated on his mother even after her death. He killed women, plundered graves, sewed a female 'skin vest' out of flesh and hung 'the faces of nine women, carefully dried, stuffed with paper and mounted like hunting trophies on the wall' (192). Robert Bloch himself plainly states in his essay, 'The Shambles of Ed Gein' (included in Lambs to the Slaughter, a collection of essays by fictional authors writing about true-crime), that the case of Gein inspired him to write Psycho:

What interested me was this notion that a ghoulish killer with perverted appetites could flourish almost openly in a small rural community ... The concept proved so intriguing that I immediately set about planning a novel dealing with such a character. In order to provide him with a supply of potential victims, I decided to make him a motel operator. Then came the ticklish question of what made him tick - the matter of motivation. The Oedipus motif seemed to offer a valid answer, and the transvestite theme appeared to be a logical extension.

(Lambs to the Slaughter, 25-26)

This overlapping of the fictional with recourse to factual narratives and events is a strong characteristic of serial killer fiction. What differentiates serial killer fiction and literary serial killer fiction from other genres, that are also informed by real-world events and characters (historical fiction being a case in point), is the particular attention paid to the psychological analysis of violent individuals and their actions. For example, when constructing the psychopathic character of Lou Ford in The Killer Inside Me, Thompson had ample personal experience to work with. His father was an Oklahoma marshal and Thompson was born in an apartment above a County Jail in 1906. Thompson's memoir, Bad Boy, and the comprehensive biography written by Robert Polito, Savage Art, suggest that his father was a harsh and menacing figure that would influence Thompson's life and writings.

In Ellroy's Killer on the Road, he used the novel to push genre boundaries by experimenting with narrative styles and tropes, but he also incorporated elements into the work 
that were culturally relevant at the time. For example, the title 'Killer on the Road' seems a direct reference to The Doors' song about a serial killer: 'Riders of the Storm.' As Steven Powell suggests in James Ellroy: Demon Dog of Literature, the exact phrase can be found in the line, 'there's a killer on the road. His brain is squirmin' like a toad.' Powell also notes that the song, and by inference, Ellroy's novel, "was inspired by the crimes of the American hitchhiker and murderer William 'Billy' Edward [Cook]”' (34). Ellroy also references the infamous Tate/LaBianca murders by Charles Manson in the novel many times. The fact that Killer on the Road is a novel about homosexual serial killers (the lead character, Martin Plunkett teams up with another serial killer, Sergeant Ross Anderson), is also another allusion to a serial killing phenomenon that was becoming more prevalent in America in the late 1970s-1980s. According to Michael Newton in The Encyclopaedia of Serial Killers, homosexual 'kill teams' such as 'The Freeway Killer' William Bonin and his accomplice/s (81); Randy Kraft, 'The Scorecard Killer,' another serial killer who had accomplices (148); and Lawrence Bittaker and Roy Norris who were known as 'The Toolbox Killers' (21) all used vans to kidnap and kill their victims; this method of operation parallels Plunkett's own in the novel. Ellroy's portrayal of Ross Anderson, the serial killing police officer, is also an interesting variation of the trope established by Thompson's characterisation of sheriff Lou Ford as a serial killer lawman, or figure of authority.

Another example (not discussed in depth in this thesis) is Oates's Zombie which is directly 'inspired by the doings of [serial killer] Jeffrey Dahmer,' (Schechter: 392). In an essay titled 'No Other Thrill of Happiness,' Oates explicates on the myriad possibilities of the serial killer as both fictional and factual trope, in terms of the reasons behind their actions. In doing so she gives an outline of Zombie's core thematic concerns:

How does one confront a zombie son with no interest in educating or training himself, no friends, no future? Is it a defective gene? Or simply bad luck? The blunt fact of Jeffrey Dahmer, as it would appear to be the defining fact for male serial killers in their adolescence, is that, while their coevals are establishing friendships that may last for decades, while they are "dating" and fantasizing romantic and sexual relations of the kind presumed "normal," the serial killer-to-be is fantasizing violent sadistic acts that empower him sexually and yearning for the day when he has the opportunity to make them real.

In an interview with Rolling Stone magazine, Bret Easton Ellis suggested that American Psycho was a direct response to the Reagan-era of the 1980s and that Patrick Bateman was the 
"emblem of yuppie despair." He goes on to cite the appropriation of gay culture as being distinct to the cultural era depicted in the novel and, in more direct terms, he: "saw him [Bateman] very much as a literary idea, a metaphor for my own life, my own pain and an overall criticism of the culture." In the same interview, Ellis acknowledges that the infamous 'rat scene' (where Bates rapes, kills and inserts a rat into a victim's vagina) was inspired by a similar incident in the narrative works of the Marquis de Sade. Throughout the novel Bates references many instances of real-world serial killer cases and his crimes seem to be a catalogue of the many types of murder committed by different serial killers, rather than representing any particular type of killer which is typical of many serial killer fiction. Rather than an attempt at validating the legitimacy of Bateman as a serial killer, the juxtaposition of factual and fictional references in Ellis's novel is more symptomatic of cultural appropriation than anything else. This apparently ironic undermining of basic realist aspirations, combined with a metanarrative pastiche of elements tinged with cold war paranoia and social dysfunction, identify American Psycho as the most postmodern of all three works of literary serial killer fiction under analysis in this thesis. Trying to align Bateman with any one real serial killer, gives him a Frankensteinian allure. We can almost see the stitch marks between the layers of influence: he has the chiselled good looks of Ted Bundy, the brutality of Jack the Ripper, the suaveness of Andrew Cunanan (Versace's assassin) and so forth. Moreover, whether or not it is because of these aspects, Bateman stands as the most transgressive, and most scary, integration of fact into fiction. In this sense, he is the ultimate postmodern bogeyman - the fictional serial killer.

\section{Origins, development and critical reception}

As intimated above, under the overarching category of crime fiction, most narratives generally referred to as 'serial killer fiction' are included. It is within this context that the sub-genre, which can be categorized as 'literary serial killer fiction,' ${ }^{3}$ exists. Works that fall into this category,

\footnotetext{
${ }^{3}$ From here on, narratives that can be classified as 'serial killer fiction' generally fall under the rubric of genres or subgenres such as crime, mystery, detective or horror fiction and will be called 'serial killer fiction,' whereas works specifically categorized as 'literary serial killer fiction' are viewed as specific members of the subgenre 'literary serial killer fiction' as opposed to the more slippery and general term of serial killer fiction.
} 
characteristically exhibit a shift away from more formulaic representations of multiple murder common to contemporary crime, mystery and detective fiction. This subtle, but discernible, point of difference from established narrative traditions signals the development of a subgenre that employs the serial killer as a central motif in a distinctive fashion. The main point of difference, between mainstream fictional representations of serial killers and those found in literary serial killer narratives, is the usage of modernist literary tropes, such as first person narration, stream of consciousness and interior monologue; combined with ontological postmodern concerns and conceits that deal with surfaces, fragmentation and subjectivism. These works are also characterised by technical innovation, sociological and psychological hermeneutic influences, and a self-consciousness that informs the narrative. This combination of factors, in relation to the primary works selected for this study, differentiate the narratives from more typically formulaic genre fiction and emphasize the emergence of a particular type of serial killer fiction. Namely, literary serial killer fiction. In the context of post-war American literary and social history (particularly, 1950-2000), of primary interest to this study are the origins and development of this subgenre as a postmodern phenomenon.

In America after the onslaught of the Second World War, a new breed of novelist emerged who portrayed murder in a more graphic and intimate fashion than was previously common. Perhaps as a result of the extreme violence, proximity, and influence of two world wars during a relatively short period in human history, murder used as a trope in genre fiction increased to the point where multiple murder took precedence over the single act of killing that was the common mainstay of mystery and crime novels. Within this context, crime fiction (a broad category encompassing noir, pulp, mystery, traditional detective, 'hardboiled,' murder, thriller, horror, psychological thriller, and the investigative police procedural) began to include narratives featuring serial killers, or 'multiple murderers' as they were known at that time. Encouraged by a reading public with a seemingly endless interest in the subject of human violence (particularly, murder), the publication of novels featuring serial killers became more prevalent and complex in terms of character, real-life comparisons, and narrative style. As Christina Gregoriou suggests in Language, Ideology, and Identity in Serial Killer Narratives: "as serial killing narratives have proliferated and become more sophisticated, the emphasis has fallen upon the complex physiologies and repetitive methods of those conducting the murders" (4). These developments also paralleled an increase in media coverage of factual cases which added 
to a growing milieu of general cultural knowledge and interest, stemming from the representations of serial killers by authoritative agencies such as the FBI (Jenkins, 1994: 55; Seltzer, 1998: 16; Schmid, 2005: 88).

A significant increase in narratives dealing with multiple murder during the post-war period in America, signalled the arrival of serial killer fiction. However, interest in narratives that deal with murder directly relates to a more universal fascination with the extreme ends of human experience, and also serves as a reason why serial killer narratives are popular as expressions of this aspect of humanity. In a contemporary context, this fascination is evidenced by the large volume of fiction devoted to the subject of multiple murder, especially within the crime fiction and true crime categories, and it is within this context that serial killer fiction has emerged as a discernible literary movement. The American post-war period was the locus of this development and saw the publication of serial killer narratives that could be categorised as two distinct, but related, subgenres of crime fiction. The more typical serial killer fiction narratives portray stereotypical representations of serial killers, which are easily aligned and categorized under the auspices of crime fiction and other genre fiction. These examples commonly use the trope of the serial killer as a plot device in a formulaic way and relegate the character to the secondary role of antagonist. In A Companion to Crime Fiction it is suggested that serial killers don't usually assume the central role in novels that feature representations of multiple murder and that "their incorporation into the structures of investigative fiction, however, can be more than formulaic, and the tendency to give the transgressor a voice has been one of the elements associated with an increased Gothicizing of investigative crime novels" (41). In the same compendium, Joel Black identifies serial killer narratives as bridging fact and fiction, with an emphasis on the transgressive potential of the trope of the fictional psychopath in crime fiction and the greater postmodern society:

The murderous protagonists in these works "mimic," and thereby expose, a morally bankrupt society where aesthetic concerns with sensation and appearance have fully eclipsed any sense of ethics and social responsibility. In these neo- noir fictions, psychopathic killers have replaced detectives as agents of revelation in a world where redemption no longer seems possible. All that is left for literary and popular writers of crime fiction to do is to expose the bustling world that we know for the fiction it is, and to reveal the real world as the deserted cityscape that it has become. (85) 
The other discernible branch of serial killer narratives that emerged from post-war America, are works that can be seen as more complex, in both style and content, and that counter the formulaic aspects of more typical crime fiction. These narratives are situated as the product of a specific American literary and social movement and are the central concern of this study; examples of which are referred to as literary serial killer fiction. While examples of literary serial killer fiction are relatively recent phenomena, most fictional serial killer narratives are informed by literary convention in crime fiction and the horror genre, with a lineage that extends back to folkloric and Gothic traditions from earlier centuries. As Philip Simpson observes, nineteenth and early-twentieth century representations of supernatural grotesquery such as vampires, werewolves and demons, easily translate "into the contemporary serial killer beloved of journalistic tabloids, hit movies, and best-selling novels. He is a neo-Gothic villain and demon. That the contemporary serial killer inhabits Gothic territory so easily is no accident" (Psycho Paths, 14-15). Philip Jenkins also suggests that representations of serial killers in contemporary narratives, function as embodiments of societies" "worst nightmares and fantasies . . . [incorporating that which] in other eras or other regions might well be fastened onto supernatural or imaginary folk-devils - vampires, werewolves, witches, evil sorcerers" (Using Murder, 112113). In this regard, the fictional serial killer is another iteration of those Gothic figures that terrify by transgressing familiar boundaries. Direct parallels between Gothic narrative conventions and serial killer fiction, can also be found in the thematic and motivic emphases on death, evil, and taboo subjects, along with the representation of the 'monstrous' in human form.

While the fictional serial killer can be viewed as a contemporary extension of Gothic and folkloric traditions, it can also be aligned with the transgressive figure of the 'bogeyman.' As Marina Warner suggests, "above all current manifestations of the bogeyman, the threat posed by serial killers ... today can put the phantasmagorias of the past into perspective" (No Go The Bogey Man, 384). Thus, the serial killer is useful as a symbolic figure of human fear, both in fictional and factual narratives, to perpetuate a longstanding human preoccupation with perceived threats to ethics and mortality. Philip Simpson offers the suggestion that "serial killers, through the heinousness of their acts, defy ready understanding and to observers confirm the darkest fears about human nature" (14). He goes on to suggest that as "an updated version of the murdering bogeyman, the serial killer lurks in the shadows of communal existence, taking down those who stray from the herd" (15). Emphasizing this overlap of tradition, fact, and fiction, 
Gregoriou observes that there is little linguistic variation in relation to the portrayal of serial killers across both fictional and factual narratives (2011:164). It is my contention that these observations (by Gregoriou and Simpson) pinpoint two significant reasons why serial killers, as they are portrayed in fictional narratives, are effective characterisations of the human propensity for 'evil'4 and, subsequently, generate critical interest and appeal to a large audience because of the association with longstanding cultural traditions.

Despite the controversies that invariably surface around the release of works featuring serial killers, serious critical responses to the study of serial killer fiction are relatively few. The studies most relevant to this discussion include Jane Caputi's The Age of Sex Crime, Mark Seltzer's Serial Killers: Life and Death in America's Wound Culture, David Schmid's Natural Born Celebrities: Serial Killers in American Culture, and Philip L. Simpson's Psycho Paths: Tracking the Serial Killer Through Contemporary American Film and Fiction. One of the first serious critical responses to serial killer fiction is Jane Caputi's The Age of Sex Crime (1987). This important work discusses the prevalence of patriarchal violence and misogyny in the form of sex crime, especially in relation to serial murder. Caputi explains how, in both factual and fictional terms, the subject of serial killing has been mythologised through tabloid journalism and popular culture to the point where the serial killer has attained the status of celebrity and cultural icon. Her feminist critique provides a political analysis of how sexual violence, particularly serial sexual homicide, has been incorporated into the Western cultural vernacular.

One of the more important observations Caputi posits is that, beginning with the infamous crimes and subsequent representations of Jack the Ripper, the serial killer has become a recurring motif throughout most media forms. The advent and growth of this phenomenon, Caputi suggests, represents a patriarchal response to the rise of the suffragette and women's rights movement. Evidenced by the mass-production and consumption of these types of narratives, it is hard to dispute Caputi's central tenet that Western culture validates and perpetuates depictions of patriarchal violence towards women. This aspect of her inquiry is especially poignant in regard to the majority of narratives that depict violence against female victims, especially as they relate to serial killer fiction. The works I have chosen for this

\footnotetext{
4 'Evil' in this respect meaning 'profoundly wicked and immoral' as defined by the Oxford English Dictionary. Source: https://en.oxforddictionaries.com/definition/evil
} 
discussion demonstrate that while many works within the genre reflect Caputi's assertion, the transgressive potential of fiction allows some authors to manipulate the figure of the serial killer to challenging effect. My own analysis draws on Caputi's historical mapping of the rise of serial murder in fictional works and the feminist critique she espouses is relative to Ellis's American Psycho and to aspects of the other titles discussed in this essay.

An important work that situates the serial killer as a typically postmodern and culturally constructed figure, symbolically representative of a fractured American society, is Mark Seltzer's Serial Killers: Life and Death in America's Wound Culture. Seltzer discusses the serial killer as a by-product of a post-industrial era where technology and the media create an instability of identity and a 'machine culture' that allows the serial killer to exist and feed from the culture. For Seltzer, the wounded body stands as an analogy for a fragmented social identity in the culture at large and, more specifically, in the serial killer persona which "has its place in a culture in which addictive violence has become a collective spectacle, one of the sites where private desire and public fantasy cross [...] In wound culture, the very notion of sociality is bound to the excitations of the torn and opened body, the torn and exposed individual, as public spectacle" (253).

Seltzer's focus suggests that serial killing is a by-product of American 'wound' culture and representative of a response by a post-industrial society seeking to define itself against a backdrop of violent cultural history. He suggests that the fascination with violent spectacle, is symptomatic of a people who have collectively created an identification with that violence as representative of their own fragmented society. He cites this junction as the locus of the perpetuation of violence, in both action and spectacle: "[ $\mathrm{t}]$ he crowd gather[s] around the fallen body, the wrecked machine, and the wound has become commonplace in our culture: a version of collective experience that centres the pathological public sphere" (22). Seltzer's analysis suggests that these 'spectacles of persons, bodies, and technologies that make up a wound culture' are responses to the trauma and social insecurity of the postmodern era. Consequently, from within this cultural milieu, or 'pathological public sphere,' the serial killer 'finds its place.' I agree with Seltzer et al, that the allegorical figure of the serial killer is an apt amalgam of contemporary American social fears, concerns and morals.

Ellis's novel American Psycho, with its strong emphasis on consumerism combined with ultra-violence narrated in graphic detail by serial killer Patrick Bateman, leads Seltzer to identify 
this combination as representative of the fascination with, and production of, representations of graphic death, "particularly in correlating economic and sexual motives [...] re-enacted in scenarios of addictive violence" (65). Seltzer's claims, concerning the conceptualisation of the relationship between mechanized and repetitive violence and culture in post-war American society, prove a useful starting point for a discussion of serial killer fiction, especially Ellis's American Psycho.

David Schmid's Natural Born Celebrities: Serial Killers in American Culture situates the serial killer as an exemplar of celebrity, within the context of the American fascination with media portrayals of violence. For Schmid, American public and media fascination with the figure of the serial killer is indicative of a "complicated relationship with celebrities, affective as well as intellectual, composed of admiration and resentment, envy and contempt, provid[ing] us with a lexicon through which we can manage our appalled and appalling fascination with the serial killer" (25). Analysing the genesis of the serial killer as a (pop) cultural icon, distinctively American in construction and appeal, Schmid concludes his critique by arguing that post-9/11 media representations have transformed the serial killer into an artefact of 'Americana' (256). 5

Philip L Simpson's Psycho Paths: Tracking the Serial Killer Through Contemporary American Film and Fiction is the most articulate analysis, in terms of the overview it provides of the post-war evolution of the serial killer fiction genre. I concur with his argument that the serial killer character can be manipulated as a political and ideological cipher, especially in fictional works. By extension, this aspect of serial killer fiction indicates its utility as a malleable trope that is culturally relevant and popular. In this respect and in line with my own conclusions about serial killer fiction, the capacity of the fictional serial killer to embody human evil, ensures its lasting appeal and identification to an audience already influenced by generations of social fear and anxiety.

5. Schmid argues that the killer's very familiarity as part of American culture serves to place the serial killer in a position capable of reinforcing recognisable American violence in the face of a new and unfamiliar threat, namely terrorism. Despite Schmid's assertion that the rise of the Terrorist as the ultimate embodiment of human evil has changed the status of the serial killer in American culture from outsider to insider (that the serial killer has become internalized by the culture from where it originates, because the perceived threat of the terrorist has now subsumed the past threat to American society by serial killers), his view does not allow for the transgressive nature of the serial killer and the continuing prevalence of both factual and fiction serial murder that occurs inside and outside the United States. Rather than the contemporary view proposed by Seltzer, Schmid's conclusion repositions the serial killer as a 'folksy figure of the past.' 
Simpson's identification of particular categories and thematic or structural patterns within serial killer fiction is also particularly useful in confirming my own position regarding the emergence of a literary serial killer fiction subgenre. He identifies four different 'movements' within serial killer fiction; the first being the 'neo-Gothic' which relies heavily on Gothic and horror genre conventions, especially as they relate to the interaction between killer and victim and the presentation of 'haunted landscapes of taboo violations and border transgressions;' the second is the detective or police procedural which follows traditional crime fiction patterning and allows equal text to both the killer and the investigator; the third movement is that of the 'psycho profile' which "centers upon the killer as protagonist, either placing the audience directly into the murderer's point of view or somewhere close by, through friends, lovers, acquaintances, or victims;" and the fourth movement is the 'mytho-apocalyptic' which recontextualizes or decontextualizes the serial killer from the historical moment in an attempt to give the killer a kind of apotheosis as a demonic messenger" (25). In addition to these four movements identified by Simpson, I have identified a small number of narratives that include these characteristics but that also exhibit their own unique features. As a result, I submit a fifth category for consideration, that which I have named: literary serial killer fiction. Most clearly aligned to the third movement of 'psycho profile' narratives, the narratives I identify as literary serial killer fiction are few in number but possess both corresponding and differential values that can be classified as a particular variation of serial killer fiction.

\section{Postmodern influences}

The common usage of realistic aspects in most serial killer fiction, to accentuate the believability and atmosphere of the narrative, antithetically counters the logic of postmodernism. However, this is more of an extension of serial killer fiction's relation to true-crime narratives, than a symptom of a narrative style uncommon to postmodernist literature. As mentioned earlier, most works of serial killer fiction show recourse to factual crimes and criminals, effectively using these real-world examples as templates for fictional representations. A characteristic of literary serial killer fiction also implies the factuality of the narrative by the use of stream-ofconsciousness, first-person perspective, and interior monologue to represent an accurate portrayal of the psychopathology most common to serial killers (in accordance with factual 
representations). In this regard, the interiority is not necessarily unique in that other genres use the same devices (especially in Modernist literature), but it is nonetheless a defining characteristic of literary serial killer fiction. Other deviations from standard postmodern narrative features found in literary serial killer fiction, include the citation of factual police procedures, scientific, psychoanalytical theory and practice, legislation, and historical events. While these aspects show that not all features are purely postmodern in characteristic, the earliest examples of literary serial killer fiction reflect the intersection of genre boundaries. For example, Thompson's The Killer Inside Me is an expression of this shift between institutional modernism to the new postmodern and paranoid sensibility of the post-war era, This development was representative of a postmodern movement that, according to Fredric Jameson, in Postmodernism, Or the Cultural Logic of Late Capitalism, is defined by the use of "obscurity and sexually explicit material to psychological squalor and overt expressions of social and political defiance, which transcend anything that might have been imagined at the most extreme moments of high modernism" (3).

Literary serial killer fiction can be read as a reaction against the decay and fragmentation of Western Culture, similar to the concern found in modernist literature such as T.S. Eliot's 'the Hollow Men,' or 'The Wasteland,' but there is a subtle difference. While borrowing techniques and motifs from modernist literature, what determines literary serial killer fiction as a postmodern phenomenon, is the way in which this reaction is tempered by a reliance on narrative devices that subvert convention and the relationship between reader and text. Moreover, while both modes employ subjectivism as a reaction to realism, by emphasizing individual through the use of stream of consciousness and the exploration of existential themes (such as alienation, death, meaningless, anxiety, and absurdity), literary serial killer fiction distances itself from any existential search for meaning and, instead, resigns itself to representing 'what is,' rather than the modernist epistemological search for 'what could be.' This aspect of literary serial killer fiction is apparent in the earliest work of Thompson, but is a lot more discernible in the later works of Ellroy and Ellis where any search for meaning is abandoned, for a portrayal of the individual who revels in the meaningless of life and death in contemporary society. While existential questions might be posed in literary serial killer fiction, the nihilistic tendencies and actions of the serial killer leave any answers up to the reader to determine. 
These aspects of literary serial killer fiction, while serving as syllogistic bases for classification's sake, are also indicators of the genre's locus as a form of a postmodern movement in American literary history. Frederic Jameson suggests that similarities and differences between modernist and postmodernist interpretations of existential ideologies, only vary in degrees in relation to time and place within capitalist society:

if the great negative emotions of the modernist moment were anxiety, terror, the beingunto-death, and Kurtz's "horror," what characterizes the newer "intensities" of the postmodern, which have also been characterized in terms of the "bad trip" and of schizophrenic submersion, can just as well be formulated in terms of the messiness of a dispersed existence, existential messiness, the perpetual temporal distraction of post-sixties life. Indeed, one is tempted ... to evoke the more general informing context of some larger virtual nightmare, which can be identified as the sixties gone toxic, a whole historical and countercultural "bad trip" in which psychic fragmentation is raised to a qualitatively new power, the structural distraction of the decentered subject now promoted to the very motor and existential logic of late capitalism itself. (Postmodernism...116)

Considering Jameson's observation, literary serial killer fiction's alignment as a postmodern narrative affords no separation between a contemporary 'nightmarish' society and the fictional serial killer. In this regard, society is complicit in the crimes; however, as a consequence, literary serial killer fiction does indeed imply an ethical imperative. The serial killer is the society and, as such, is a much more poignant portrayal than those representations found in general works of serial killer fiction. I argue that this potential for self-reflection, mainly because of the blurring of boundaries between reader and text, increases the potency of literary serial killer fiction as a viable genre worthy of discussion. This disintegration of boundaries between literary and social conventions, text and reader, is symptomatic of what Philip Simpson refers to as the fluidity of the "postmodern mind-set." He positions this claim in terms of the relationship between serial killer narratives and postmodernity, as a cultural and literary influence:

The postmodernist aesthetic diligently effaces boundaries, such as the modernist elitist privileging of high art over the easily attained pleasures of low and or a clear-cut separation between inner phantasms and outer reality ... The contemporary postmodernist, while still working within the cultural grand-narrative of modernism, has accepted the political agenda-popularized during the middle of the twentieth century but partially anticipated in many earlier literary and philosophical formulations of challenging all epistemological 
limits ... without necessarily deposing them. But because this transgression of all boundary is inherently a "violent" act of cognition, mature postmodernitv as a cultural force evokes a crisis-as-spectacle atmosphere ... in which literal violence as well as increasingly sensational narrative representations of it can easily flourish. Thus, the proliferation of serial-murder narratives over the past decade and a half should be perceived as one specialized branching of a more generalized movement toward violent spectacle in the arts.

(Blurring all Boundaries, 5-6)

Determined by the critical views cited and my own research, it is my contention that the post-war development of literary serial killer fiction as a genre, can best be explained in terms of social and literary contexts that influenced the development of narrative works that can be classified as members of this category.

\section{The lineage of folklore, the Gothic and true crime narratives}

Examples of the Gothic portrayal of a human monster can be found across most literary genres, but are a defining staple characteristic of serial killer fiction. Mary Shelly's Frankenstein, for example, can be seen as an early characterisation of the serial killer as a human monster that borders on the supernatural in its depiction of the romantic grotesque. While the human qualities are still present in the creature, as soon as it murders someone it becomes transformed into a monster with the use of Gothic rhetoric. It is this type of monster - part human, part beast, or supernatural entity - which paved the way for the modern/contemporary version of the fictional serial killer, yet it was not until the sensational crimes of 'Jack the Ripper' were reported by international media, did the public so deeply engage with the world of the serial killer. As Caputi suggests, "it was not until 1888 in London that this new type of crime entered and transformed mass cultural consciousness," (The Age of Sex Crime, 5). With the proliferation of graphic reportage surrounding the serial murders of Jack the Ripper, catering to the public's fascination for narrative depictions of torture and violent crime, it was inevitable that authors realized that readers were prepared to pay for fictional representations of such crimes and criminals.

The representation of homicide is common amongst many different genres; main proponents of murder as a literary device are those authors who write within the mystery, crime, detective, western, thriller, horror, adventure, fantasy and Gothic fiction genres. In David Buss's The Murderer Next Door: Why the Mind is Designed to Kill, he states that crime statistics 
suggest serial murder occurs rarely, when compared to single incidents of homicide, only " 1 or 2 percent of all homicides" (219) are committed by serial killers. This reality is not reflected in contemporary works of crime fiction, where serial murder prevails as the type of murder most often represented. The majority of contemporary best-selling fictional crime novels (including mystery, detective and thriller), typically involve the use of a serial killer antagonist or protagonist engaged in a battle of wits with the lead investigator. Mainstream authors like James Patterson, Lee Child, Patricia Cornwall, and Jeff Lindsay have all made successful careers out of repeating formulaic 'serial killer vs anguished detective' stories.

As suggested, many fictional serial killer narratives are informed by their true crime counterparts. Infamous serial murder cases dating back to the nineteenth century like the unsolved 'Jack the Ripper' murders, Sweeney Todd, or, more recently, serial killers such as Jeffrey Dahmer and Ted Bundy, are oftentimes the inspiration for fictional tales of serial murder. For example, Joyce Carol Oates's Zombie was inspired by the crimes of Jeffrey Dahmer; Robert Bloch's Psycho, the serial murders of Edward Gein. The reason behind the proliferation of fictional serial killer narratives can be traced to the public's continued fascination with sensational media reporting and tabloid journalism that focuses on serial murder. Despite a decrease in instances of serial murder in the past decade, the reading public's fascination with serial killer narratives still maintains a steady trajectory that propels works of note onto the bestseller lists on a regular basis. Ever since the notorious crimes of Jack the Ripper were reported in every major international newspaper of the late nineteenth century, the mysterious and deadly figure of the serial killer has held the public's attention. There is an element of the voyeuristic thrill involved, in that while what is shown is horrific, it is just too compelling to look away or ignore.

One of the earliest instances in narrative history, acknowledging the human propensity for a fascination with violence and death, is Plato's recounting of Socrates's tale of Leontius, the son of Aglaion, who witnesses a pile of corpses after a mass execution. Overcome with a desire to gaze upon the violent scene before him, he is torn between a sense of propriety and dread intermingled with morbid curiosity: "for a time he struggled and covered his eyes, but at length the desire got the better of him; and forcing them open, he ran up to the dead bodies, saying, Look, ye wretches, take your fill of the fair sight" (The Symposium, Book IV). This testament to the power of spectacle over the imagination, particularly in regard to scenes of violence and 
death, allegorises a fundamental aspect of the human interest in the subject. Edmund Burke also records an early historical observation of human (morbid) curiosity, in relation to scenes of death and violence. Here he points to the cathartic effect of such phenomena, as being the primary cause behind our engagement with it, as common to:

the greater part of mankind; there is no spectacle we so eagerly pursue, as that of some uncommon and grievous calamity; so that whether the misfortune is before our eyes, or whether they are turned back to it in history, it always touches with delight. This is not an unmixed delight, but blended with no small uneasiness. The delight we have in such things hinders us from shunning scenes of misery; and the pain we feel prompts us to relieve ourselves in relieving those who suffer; and all this antecedent to any reasoning, by an instinct that works us to its own purposes without our concurrence.

(The Works of . .., Section XIV)

This element of human interest in the reportage of violent spectacle is, in my view, the basis for the continued appeal of both factual and fictional representations of serial murder which are invariably graphic. This presumptive knowledge of human interest in violence, combined with the use of literary device and technique to emphasize this aspect in fictional and factual stories - is commonly employed by authors to present cases to the reading public in a way by which the common-place and mundane aspects of both crimes and subsequent investigations are made more interesting. Aside from the drama and tragedy of the crime and the effect on people (including victims and their families and investigators and their families), the majority of procedure and investigation is laborious and boring work that would make for extremely tedious reading if written in a purely objective and factual style. Like serial killer fiction, the line is blurred between fiction and non-fiction; through the use of literary (fictional) tropes and technique, true crime stories present the 'facts' in much the same way that genre-fiction narratives use similar methods to create fictional experiences.

Authors of serial killer fiction typically attempt to differentiate their narratives by producing the latest and most violent representation of serial murder available. Unfortunately many of these works, as Michael Morrison suggests in A Dark Night's Dreaming: Contemporary Horror Fiction, "display an appalling atrophy of the imagination. Their authors seem to operate on the assumption that the mere mention of a psychopath or serial killer, accompanied by graphic renderings of diverse atrocities, suffice to make a successful horror novel" (24). Somewhat different from this negative strain of serial killer fiction, are the more cerebral works of literary 
serial killer fiction which typically favour stylistic innovation and characterization to enhance the narrative. Writers in this genre seemingly differentiate themselves from standard crime novels and the more generalized serial killer fiction, by adopting interesting shifts in perspective and other devices, favouring the literary over the literal.

The strongest examples of literary serial killer fiction rely on a first-person narration that encourages the reader to get inside the mind of the murderer. This emphasis on the perspective of the killer, potentially allows the reader to experience a deeper involvement with the terrible crimes of serial homicide, from the point of view of the perpetrator. The influence of early works that employ this technique, such as Jim Thompson's The Killer Inside Me, can be traced through a number of subsequent works that similarly relied on first person perspective and a reversal of the more traditional roles of protagonist and antagonist. As the popularity of such narratives increased, later works would subvert this method yet again to stamp their own mark on the growing subgenre.

More general examples of serial killer fiction, however, rely on established genre tropes and literary devices in order to enhance the reading experience in terms of action, pacing and sympathetic characterisations. In these instances, the common fictional depiction of serial killers are typically caricaturised as a mythological figure with little resemblance to its real-life counterparts, more in line with past representations of Gothic monsters and supernatural beings. This aspect of serial killer fiction represents the significant influence of folkloric traditions that were transmitted through Gothic literary conventions. Philip Jenkins observes that serial killer fiction "reduces a quite complex social and behavioural problem to a personalized, almost gladiatorial conflict between individual heroes and villains, and both sides are presented in accordance with very traditional images and stereotypes" (Using Murder, 111). He goes on to say that in these instances, the serial killer is represented "in the most frightening and threatening manner conceivable, as totally other as can be imagined." Furthermore, "in achieving such monstrous images, contemporary constructions of the serial murder phenomenon have much in common with mythological types from many different societies and eras" (111). This resonantly mythical symbology contributes to its appeal to the masses' folkloric sensibility in what Jenkins cites as an identifiable "set of fixed tale types that generate an endless stream of what are in effect variants: sequels, remakes and ripoffs" (112). 
As suggested by Jenkins, the propagation of myth surrounding representations of serial killers is perpetuated by these formulaic conventions, but is also utilized deliberately to promote seriality within these narratives. This aspect of serial killer fiction is a good indicator of why so many of these texts operate as works within a series. For instance, Patricia Cornwall's 'Scarpetta' series, Jeff Lindsay’s 'Dexter novels, Jeffrey Deaver's 'Lincoln Rhyme series, and the most well-recognized fictional serial killer, Hannibal Lecter, in Thomas Harris's 'Lecter trilogy,' all employ formulaic representations of the serial killer. Usually this representation stereotypes the serial killer as almost super-human, highly intelligent, and capable of the most sophisticated actions and thoughts. The protagonist, usually the detective attempting to capture the killer, also typically relies on clichéd characterisation and plot devices to steer the narrative towards an inevitable conclusion. For example, common depictions of the two central characters within serial killer fiction can be seen in the drunk (or recovering drunk) detective 'gumshoe,' whose life is marred by tragedy and circumstances beyond their control. Thematic plot devices also rotate amongst the various narratives; quite often the serial killer targets the detective and/or their families, ratchetting the tension of the narrative up to the point where the ending culminates in the death of the murderer and the redemption of the detective character as he rescues/saves the final victim from certain demise. If the murderer does not die at the end of the story, inevitably he/she will rise again in a sequel or series to battle wits with the detective once again.

As public interest grew in the later-half of the twentieth-century and was perpetuated by an increase in both factual and fictional narratives focussed on serial murder, so too did the understanding of what it was that actually constituted a realistic portrayal of a serial killer. Novels also began to reference figures from the real world seemingly for the sake of verisimilitude, as David Schmid suggests, by incorporating a ready-made "identifiable cast of characters, such as Ted Bundy, John Wayne Gacy, and Jeffrey Dahmer" (15) As a result of this greater understanding of serial murder and the increased availability of legal and scientific methods and theory, the subsequent use of these non-fiction narratives within more proficient works of serial killer fiction established a new set of fictional tropes and devices that were in turn adapted and assimilated to a degree that they became defining characteristics of works within the genre. That is, what constitutes or qualifies a work of serial killer fiction, can be measured by the narrative's adherence to factual procedures, techniques, and commonly accepted truths. 
As suggested above, the central characters in most works of serial killer fiction are deliberately, or inadvertently, informed by their factual counterparts. However, despite recourse to fact, there are aspects of both character and plot that are never far from the continuing sensationalised cinematic portrayals that prove popular with the mainstream public (such as Psycho and Silence of The Lambs), which still cling to the basic formulaic precepts informing early works within the genre.

\section{Characteristics of literary serial killer fiction}

The novels I have selected for this study all adopt first person narration as part of a repertoire that is plainly designed to counter the formulaic aspects of more typical genre fiction. Narratives attempting to push the genre in new directions, in the search for originality and as a way of countering the formulaic and cliché-laden tropes that the genre characteristically produced, broke new ground by retreating into the mind of the murderer and stepping away from the use of literary convention common to crime fiction. The shift in point of view from third-person narration commonly used in mystery and crime fiction narratives, to the use of a first-person narrator who is a serial killer, can be seen in early examples such as Thompson's Killer Inside $M e$, and then later in the works of Ellroy and Ellis (amongst others). This emphasis on perspective became a defining characteristic of works within the genre of literary serial killer fiction and established a way forward that allowed authors more imaginative use of fictional tropes. Moreover, these works characteristically explore the potential for serial killer narratives to do more than merely rehearse the familiar pleasures of well-worn narrative structures. As a result, these narratives contain added dimension in terms of complex ideas, social and philosophical conceits, and the freedom to expand the narrative beyond the realm of fact. In essence, the limitations of formulaic representations of serial murder were countered by those authors who used the inner world of the serial killer to explore issues beyond those immediately implied by the novel's main action, and to open their novels to wider hermeneutic potential.

The serial killer's establishment as a transgressive representation of both true and imaginative forms of human evil, signalled the arrival of one of the most identifiable and 
common character tropes in American twentieth-century literature. ${ }^{6}$ The development of narratives classifiable as literary serial killer fiction, saw the transformation of the character of the serial killer into more than a fictional bogeyman figure that essentially functioned as a literary device to drive narrative plot. To some degree the serial killer remains symbolic in these works, yet has evolved into a more complex construct of a flawed American figure than in other works of serial killer fiction housed under the crime fiction genre. The examples of literary serial killer fiction discussed in this thesis, typically invite a more complex set of hermeneutic responses in which the serial killer figure stands as provocateur in consideration of broader social, political or philosophical questions. For example, in Chapter One, I explain how Thompson's Killer Inside Me can be read as a meditation on the brutality of power within the nihilist environment of post-war capitalist America. In Chapter Two, James Ellroy's Killer on the Road is interpreted as a discourse on the inherent violence in contemporary American society and the destruction of family values. Finally, in Chapter Three, Bret Easton Ellis's controversial portrayal of white corporate excess in American Psycho can be interpreted as a satirical indictment of American greed and capitalist debasement as embodied by the central character of Patrick Bateman. Of course, many other critical viewpoints can be applied to these works but for the sake of brevity, select examples of the most germane criticism are used to illustrate my own thoughts on the narratives selected for this essay.

I have chosen the particular works because of their complexity and their difference from the more typically formulaic, main-stream narratives of serial killer fiction found within the genre of crime fiction. This study emphasizes the functionality of these select works I classify as literary serial killer fiction, by showing that their allegorical natures allow for social and cultural commentary expressly concerned with violence, sexuality, and class while also positing philosophical questions about fundamental aspects of human nature. Narratives within the genre of literary serial killer fiction, characteristically exhibit postmodern attributes representative of the types of works that extend literary boundaries ${ }^{7}$

6. The more contemporary equivalent of this phenomenon in twenty-first century post ' $9 / 11$ ' literature, is the rise of the terrorist as the archetypal embodiment of human evil. See David Schmids 'Serial Killing in America After 9/11.'

7. McHale, Brian. Postmodernist Fiction. New York and London: Methuen, I987. Pp. 140-1 - “.... a text-length trope which preserves the two-level ontological structure of metaphor (literal frame of reference, metaphorical frame of reference), but in 


\section{Philip L. Simpson suggests in Psycho Paths: Tracking the Serial killer Through}

Contemporary Film and Fiction that the use of the serial killer in contemporary American fictions operate under the rubric of a "cultural grand narrative of "frontier individualism" (17). Indicative of an 'affirmative' postmodernism, this adaptation of the serial killer as a vehicle for socio-cultural allegories, serves to "incorporate both liberal and conservative political agendas" that challenge existing epistemological and philosophical frameworks. In this respect, serial killer fiction directly mimics the postmodern collapse of epistemological systems. Furthermore, this expression of American conservativism and individualism taps into the mass appeal of violence as a universally American social and media preoccupation, especially in explaining the growth and appeal of serial killer fiction in the nineteen-eighties and nineties:

[T] he proliferation of serial murder narratives over the past decade and a half should be perceived as one specialized branching, and not a terribly novel one, of a more generalized movement towards violent spectacle in the arts. It follows then, that the spectacular criminal, such as the serial killer, will achieve "A-List" status in popular entertainment. Contemporary serial killers in fiction resonate deeply with the American public because they so literally express what many people feel - an extreme fascination with not only the dehumanizing complexities of mass democracy ... but the representational ambiguities of the postmodern world. (17)

The enduring human interest in narratives that deal with murder, in particular serial killing, are relative to our more general fascination with the extreme ends of human experience. As outlined above and in the chapters ahead, this fascination is evidenced by the large volume of narratives available on the subject of serial murder. There are numerous critical studies that seek to explain this interest. One explanation concerns the capacity for crime narratives to reassure by modelling the restoration of order. In this regard, the murderer disrupts the social equilibrium while the detective applies rationale and uses society's mechanisms for resolving disorder with the application of law to restore social order. Another explanation is that in the character of the supremely maligned murderer we find the 'bogeyman' figure, an allegorical scapegoat who

\footnotetext{
which, instead of being announced explicitly, the two-level structure remains implicit, disseminated through the text [...] the revival of allegory in postmodernist writing can also be related to postmodernism's ontological poetics. The fictional world of an allegorical narrative is a tropological world, a world within a trope. Its ontological structure is dual, two-level, one level (or frame) that of the trope $[\ldots]$ the other that of the literal [...] where in a metaphor the metaphorical frame of reference is absent, the literal frame present, in allegory it is the literal frame of reference that is missing and must be supplied by the reader-only the metaphorical frame is given. Like metaphor, however, allegory offers itself as a tool for exploring ontological structure and foregrounding ontological themes."
} 
represents pure evil wholly 'other' to social norms. While this figure maintains and propagates fear and anxiety, it also serves to reinforce the line between self and other, society and alien threat, the human and the monstrous. Yet, as a true outsider figure, the serial killer can never be wholly neutralised or integrated by systems of social order. While these factors contributed to the integration of serial killer narratives into the public sphere, the influence of significant historical events can not be underestimated.

Following World War Two, within the overarching genre of crime fiction, a significant new subgenre began to emerge that was explicable in terms of revelations from the war, particularly the brutal serialized slaughter of humans by other humans. Yet while the mass murder of the war might explain the growing fascination with multiple killings during and after this period, there are other features of the emergent genre that require some consideration. For instance, while (as has been argued) the maligned figure of the fictional serial killer could readily be considered monstrous, many of the real-world killers that informed these narratives are distinguishable not by their irreconcilable difference but by their familiarity: in most cases they could outwardly be anyone's brother, father, or uncle. In this regard, they are in reality thus an outsider to the category of the monstrous. By casting this representation of malevolence as an insider, the fear generated was accentuated by the defining characteristic state of paranoia, a sentiment consistent with the cold war environment of post-war American society.

As much as this new approach offered the potential of transgression of established categories that use murder as a thematic motif, serial killer fiction soon established its own familiar types and tropes. The integration of serial killer fiction as a subgenre of crime fiction was, by association, grouped with a wide range of subgenre categories such as detective, mystery, horror, and pulp fiction, each with their own conventions of plot, character and stylistic conceits. This association led to subsequent integration within these subgenres and eventually to the utilization of and by other genres outside of crime fiction, as the popularity of the trope increased. This power of the fictional representation of the serial killer, is evident in the disproportionate predominance and function in crime novels. This imaginative force was further enhanced by a dynamic of mutual influence between true crime reporting and fictional accounts. As novelists sought to create more realistic interpretations of the growing phenomenon of serial murder, they drew heavily on detailed research and factual reportage. 
As the figure of the serial killer gained traction as a viable literary character, real-world serial killers accrued growing celebrity status. As a result, the focus by tabloid media on real serial killers became hyperbolic as it parasitically fed into the capacity to provoke paranoid fear. The type of paranoia generated being closely related to a fascination with conspiracy which lies in the invitation to believe - against evidence - that despite a growing sense that the world no longer follows regular, discernible patterns, someone or something still exercises control over events by scripting their apparently inchoate sequencing.

The figure of the serial killer is, by definition, one who evades capture and continues to kill, again and again. Portraying the figure as a kind of elusive genius who can predict the moves of those trying to stop him, even to the point of encouraging their pursuit by baiting them with deliberately laid clues, enhances this mythos and propagates one-upmanship in subsequent depictions. This aspect of the development of the fictional serial killer saw him (for he is invariably male) become something of a counter-cultural hero: the rebellious outsider who exposes the shortcomings of systems of social order that claim to be able to contain threats. The serial killer, in this sense, is disruptive of master narratives and transgressive of social order because he utilizes the very mechanisms of social systems designed to protect the individual against danger.

Thus far, we have a picture of a transgressive figure safely contained within a formulaic genre. However, operating in parallel are some works that pick up on the transgressive potential of the characters and inherent themes and extend these tropes, to produce a disruptive reading of the social milieu of both the genre's production and its reception. The novels I examine in this thesis all exploit this particular potential of the genre of serial killer fiction, to produce something interrelated yet quite distinct. Given the reliance on specifically literary techniques (as distinct from plot and character conventions) to produce these genre-transgressing fictions, this new strain of serial killer narrative can be identified as literary serial killer fiction.

The various aspects outlined above and throughout this thesis constitute a summation of what I believe to be a previously unidentified category and sub-genre of serial killer fiction, that I call literary serial killer fiction. The relevance and popularity of the genre along with the functional aspects of the trope, lead me to conclude that it is an ideal form to interact with popular cultural narratives, while also allowing subversive interplay between both real and fictional concerns. The appeal of the genre to those authors who usually write outside of it, 
particularly in regard to its transgressive and allegorical qualities, is also of particular interest to this study. Because of the hybrid nature of the genre and the ease with which the central trope of the fictional serial killer transcends genres, the resulting possibilities provide a transgressive outlet for authors who wish to test boundaries, in both a literary and an ontological sense, in regard to the commentary serial killer fiction allows on the state of contemporary American literature and society. 


\section{Chapter One \\ Jim Thompson's The Killer Inside Me \\ - Portrait of a Serial killer}

"I'm the most cold-blooded sonofabitch you'll ever meet."

- Ted Bundy

In Jim Thompson's 1952 Novel, The Killer Inside Me, the central protagonist and narrator, Lou Ford, is revealed to be a psychopathic serial killer. Ford is the enigmatic but understated Deputy Sheriff of Central City, a small American country town. Prone to platitudes and rhetoric, he at first seems nothing more than a stereotypical characterization of an American lawman. As the title suggests, this is a narrative that depicts the inner workings of a violent psychopath. The depiction of the psychological interior of the narrator, is a complex and subversive exploration of (distinctly) American violence and genre style. Ford's figurative use of language throughout the novel mimics the violence and manipulation he enacts literally and serves to maintain the façade of the persona he has constructed as Deputy Sheriff. When words fail Lou Ford, he is left with the only form of expression he knows best: violence. As the story progresses, Ford struggles to maintain the pretence, while his every thought and action brimming with violence and a 
narcissistic sense of entitlement. This dichotomy of good and evil, truth and fiction, and appearance and self-identity, defines both the narrative and Ford's psychopathology. As Robert Polito suggests, in the prologue to his biography of Jim Thompson:

the central grotesquery of The Killer Inside Me remains Lou Ford's voice. With his shrewd mix of good cheer and hard-boiled idioms, alternatively swaggering and shrinking but always observant and self-regarding, Ford cakewalks through his story like a crafty, ingratiating con-man. As he juggles his double life, putting on himself and the reader, just as earlier he had toyed with his victims and laughed at his pursuers, you never entirely disbelieve him - although it's certain that he is giving himself away, and likely that he is a callous killer posing as a helpless psychopath" (Savage Art, 6).

The use of cliché as a rhetorical device is a mainstay of the 'dime novels' that date back to the 1860s. Significantly it is from these earlier works that fictional genres such as detective, western and horror evolved, and it is from this tradition that Thompson's own writing was influenced. Combined with Thompson's earlier experience as a writer of true crime (or 'fact detective' stories) for various publications, The Killer Inside Me combines these stylistic influences and delivers a narrative, that up until its publication, had previously not been seen. With the use of first-person narration, 'pop psychology' and genre allegory, Thompson effectively delivers the first American instance of a serial killer novel that is distinguished by a distinctively 'confessional' narrative, whereby the reader is forced to confront the world through the thoughts and viewpoint of the killer. There are earlier examples of authors, such as Ellery Queen ('Cat of Many Tails,' 1949) and Philip MacDonald ('Xv. Rex,'1933, aka 'The Mystery of The Dead Police') writing stories that deal with multiple murder or, typically, 'homicidal maniacs', but none from the perspective of a serial killer protagonist such as Lou Ford.

Ford, as the name suggests, is the quintessential representation of American values and socio-cultural production. From his unmistakably 'western' Stetson hat, to his ever-present cigar and lingual clichés, we are presented with (at first) a walking stereotype of the American 'everyman.' Ford seems to be the product of a cultural system that has given him authority to do as he will to his fellow countrymen and, more specifically, women. He wields power with a swagger, both linguistically in his quips and jibes and also literally, more akin to another great American stereotype of the mid-west - John Wayne. Ford's clichéd language also parodies the 
traditional 'gum-shoe' speech of hard-boiled detective novels and films; reminiscent of Humphrey Bogart's portrayals of flawed law-men and petty crooks.

As a literary device, this allusion to and representation of masculinity and the satirization of genre-types, also serves another purpose. That is, it emphasizes the false and deviant nature of Lou Ford. His use of cliché is deliberate and churlish, in that he speaks that way deliberately as a means to not only confuse and bully, but also to gauge response from prospective targets (including the reader). He employs this dialect as a source of pleasure; he enjoys watching people 'squirm' as he rhetorically assaults them with banal one-liners and platitudes. For example, in the following scene from the first chapter, the reader is confronted with the unusual, almost pastiche, figure of Deputy Lou Ford. Just after midnight, after making small talk with the waitress in the local diner, Ford finishes his meal and begins a dialogue with the restaurant owner. The reader learns the owner's son has had legal issues previously and that Ford has 'straightened him out.' The proprietor refuses payment from Ford and instead gives him some cigars to show his appreciation. Ford repays the man's kindness with a diatribe that is both condescending and theatrical. He begins by assuming a physical stance, typical of fictional portrayals of stereotypical western/detective lawmen: "I leaned an elbow on the counter, crossed one foot behind the other and took a long slow drag on my cigar. I liked the guy - as much as I like most people, anyway - but he was too good to let go. Polite, intelligent: guys like that are my meat" (p. 4).

After emphasizing his physical and psychological position, he launches into a dialogue with the owner. As much as his physical posturing is seen to be clichéd, so too are his words. Every line is laden with platitudes and rhetoric; the effect of which allegorizes his own characterization, as he constructs the phony façade around his true self:

'Well, I tell you,' I drawled. 'I tell you the way I look at it, a man doesn't get any more out of life than what he puts into it.' 'Umm,' he said, fidgeting. 'I guess you're right, Lou.' 'I was thinking the other day, Max; and all of a sudden I had the doggonedest thought. It came to me out of a clear sky - the boy is father to the man. Just like that. The boy is father to the man.' 
Interestingly, this quote reveals a thinly veiled reference to a line from either Wordsworth's 1802 poem, 'When My Heart Leaps Up, ' "[t]he Child is father of the Man;” or Gerald Manly Hopkins poem, which responds to Wordsworth's, 'The child is father to the man':

'The child is father to the man.' How can he be? The words are wild.

Suck any sense from that who can:

'The child is father to the man.' No; what the poet did write ran, 'The man is father to the child.' 'The child is father to the man!'

How can he be? The words are wild!

After, delivering the appropriated reference about the 'child being the father of man,' Ford quips that he "should have been a college professor," his feeling of power over the proprietor evident in his self-aggrandizing:

The smile on his face was getting strained. I could hear his shoes creak as he squirmed. If there's anything worse than a bore, it's a corny bore. But how can you brush off a nice friendly fellow who'd give you his shirt if you asked for it?

'I reckon I should have been a college professor or something like that,' I said. 'Even when I'm asleep I'm working out problems. Take that heat wave we had a few weeks ago; a lot of people think it's the heat that makes it so hot. But it's not like that, Max. It's not the heat, but the humidity. ''ll bet you didn't know that, did you?'

He cleared his throat and muttered something about being wanted in the kitchen. I pretended like I didn't hear him. (4-5)

This sense of Ford's belief in his superiority, signals another aspect of his psychopathology as he continues to 'strike' at the man, with more pompous expressions of his intellectual and linguistic prowess. Psychopaths are notoriously grandiose in their narcissistic perception of themselves as the most important. ${ }^{8}$ Indeed, when one consults the main psychiatric textbook that Ford often references (Emil Kraepelin's Clinical Psychiatry), apt description of his

8. "Traits that are common among psychopathic serial killers - a grandiose sense of self-worth, persuasiveness, superficial charm, ruthlessness, lack of remorse and the manipulation of others..." Adapted from The Wisdom of Psychopaths, by Kevin Dutton, by arrangement with Scientific American/Farrar, Straus and Giroux, LLC (US)

http://www.nature.com.helicon.vuw.ac.nz/scientificamerican/journal/v307/n4/full/scientificamerican1012-76.html 
character can be found easily enough. This passage in particular, describes Ford's use of language above, combined with his narcissistic self-importance: "They believe their English the best; they speak as fluently several other languages; their voice is clear and distinct and can be heard for many blocks, because of its excellent qualities . . . can deliver an oration on any subject." 9

Ford continues talking at the bewildered proprietor. A banal reference to 'the weather' and a vague allusion to the Wordsworth poem is made once again as he serializes his own clichés. The reference to the 'rainbow' and finding the positive in the negative ("every cloud has its silver lining"), subverts the meaning of the expression. He further emphasizes the logic of the psychopath; justifying the negative as being essential for the presence of the positive: "if we didn't have the rain we wouldn't have the rainbows ..." As the proprietor ('rainbows') can be read as the antithesis of Ford's character ('rain'), this use of allegory represents the otherness of 'rubes' ${ }^{10}$ in The Killer Inside Me. That is, normal people.

Obviously, this kind of interpretation is vague without context, but by the end of the novel the reader should see that Ford's logic and language are skewed and that these early passages signal this aspect of the narrative:

'Another thing about the weather,' I said. 'Everyone talks about it, but no one does anything. But maybe it's better that way. Every cloud has its silver lining, at least that's the way I figure it. I mean, if we didn't have the rain we wouldn't have the rainbows, now would we?'

'Lou ...'

'Well,' I said, 'I guess I'd better shove off. I've got quite a bit of getting around to do, and I don't want to rush. Haste makes waste, in my opinion. I like to look before I leap.'

9. Kraepelin, Emil, trans. A. Ross Diefendorf, Clinical Psychiatry: A textbook for students and physicians, London: Macmillan \& Co, 1912.P. 302.

10. In another important section, Ford explains how he came to be Deputy Sheriff and his father's high expectations of him in terms of his career: "Dad had wanted me to be a doctor, but he was afraid to have me go away to school so he'd done what he could for me at home. It used to irritate him, knowing what I had in my head, to hear me talking and acting like any other rube around town. But, in time, when he realized how bad I had the sickness, he even encouraged me to do it. That's what I was going to be; I was going to have to live and get along with rubes. I wasn't ever going to have anything but some safe, small job, and I'd have to act accordingly. If Dad could have swung anything else that paid a living, I wouldn't even have been as much as a deputy sheriff." $(27-28)$ 
Concluding his conversation with the proprietor, Ford sums up his reasons for using such language, with a final string of platitudes. It is at this point that his rhetoric becomes plain, the clichés disappear but the language is still heavy with allusion and implied meaning.

Significantly, the reader has been told and shown, that the narrative ahead will be as figurative as it is literal. This use of rhetoric serves to define him as an archetypal American lawman, as commonly depicted in pulp western/detective fictions. However, it also signals a deliberate parody of the language used in such genre-centric portrayals. As Ford goes on to emphasize his language as exemplar of his intellectual and linguistic cunning, his use of cliché takes on a more ominous tone:

That was dragging 'em in by the feet, but I couldn't hold 'em back. Striking at people that way is almost as good as the other, the real way. The way I'd fought to forget - and had almost forgot - until I met her.

I was thinking about her as I stepped out into the cool West Texas night and saw the bum waiting for me. (5)

This remarkable chapter sets the scene for the rest of the novel. Along with the subtle and critical narrative connections, the reader is given an indication of Ford's true nature; cruel, manipulative and capable of violence. However, even though Ford is shown to be all these things through his speech, the less astute reader can easily interpret these traits as inconsequential, or merely representations of genre-typical narrative. As an introduction to Ford's character, the reader can be forgiven for dismissing him as a stereotypical figure whose eccentric behaviour and clichéd speech typifies him as a type of cartoonish representation of a modern deputy sheriff. However, when this section of dialogue is deconstructed (as above) and after further reading, the implied logic behind Lou's words take on different meanings altogether. It is not until the seventh chapter that the reader is privy to the nationality of the restaurant owner. Revealed as of Greek nationality, he is only described before the dialogue in chapter one as "running his words together like foreigners do." The fact that English is not his native tongue, sets the restaurant owner up as an easy foil to Ford's bombardment of dialectal colloquialisms and non-sequiturs. Every sentence Ford uses in response to the owner's polite replies, is patronizing in tone. He uses twisted logic and allusion to baffle him and expose what Ford perceives to be weakness. What is also revealed is an implied intelligence, characteristic of the fictional psychopath in most subgenre works of serial killer fiction. 
This use of implication and allusion to aspects of Ford's character early on in the novel, is a literary device that builds ambiguity and suspense into the narrative. In this respect, the reader is forced to view the main character with distrust - to interpret Ford's actions and, particularly, his speech as manipulative and potentially threatening. As the story progresses, the figurative violence of Ford's speech evolves into a more literal representation. The restaurant owner's son, 'Johnnie Pappas,' will eventually be strangled to death by Ford. The woman he is thinking about as he exits the diner is Joyce Lakeland - the prostitute that ignites the supposedly dormant 'sickness' in Ford and triggers his killing spree. The 'bum' he confronts upon leaving the diner turns out to be a pivotal character who Ford uses like a stage-prop when he finally beats to death his (Ford's) fiancé, Amy Stanton. Like all seemingly incidental characters in The Killer Inside $M e$, the nameless vagrant also proves a crucial piece of the puzzle in relation to the death of Ford's foster brother, Mike Dean.

In chapter two, the implied cruelty and violence of the first chapter, is exemplified with the savage beating of the prostitute immediately followed by a scene where Ford encounters the vagrant once again. After approaching Ford and asking for food, the deputy's response leaves no doubt as to the cruelty he is capable of as he deliberately stubs his cigar out on the man's open palm. The graphic depiction of violence with the beating to near-death of the prostitute because of a rebuke and a slap, combined with the torturous assault on the vagrant, explicitly demonstrates the protagonist's sadistically violent nature.

Traditionally, in works of mystery and suspense, the first-person narrative had been the domain of the protagonist (usually the detective). What makes Thompson's novel unique, is that he subverts this literary device to create an extremely unnerving portrayal of the inner workings of the mind of a serial killer. Lou Ford's narration not only reveals his thoughts and psychological make-up, but also shows that he has an acute sense of self-awareness about who and what he is. As much as he is aware of his propensity for violence and deviance, he makes no real effort to seek help for his malady. In terms of the psychopathology of his character, he is intelligent enough to understand that nothing he or anyone else can do will change the essential nature of himself. During a 'clean up' of the town's criminal element, Ford visits Joyce Lakeland, a prostitute who lives on the outskirts of town. After knocking on her door, he ponders how he should confront her. His thoughts reveal how much of his character is governed by how 
he thinks he should act, as both a Deputy Sheriff and as a male, and how he should appear to others:

I was feeling a little uncomfortable. I hardly knew what I was going to say to her . . . Out here you say yes ma'am and no ma'am to anything with skirts on; anything white that is. Out here, if you catch a man with his pants down, you apologize ... even if you have to arrest him afterwards. Out here you're a man, a man and a gentleman, or you aren't anything. And God help you if you're not. (8)

The assertion of his masculinity before confronting the female character is obviously stated, but the subtle implications in the context of the paragraph are far more revealing. For the first time in the novel (and relatively early on) the astute reader can catch a glimpse of the beginnings of Deputy Ford's leanings towards a psychopathic personality type. Despite the propriety he feels obliged to offer in the form of manners, he objectifies her and she becomes a 'thing' wearing a skirt; merely a class away from a black female who would not be afforded any politeness. The mention of how he should deal with males, shows that masculinity is respected at all levels in Capital City. In this sense, it is primarily a man's world and as such Ford has to act like a man in order to command respect and power. The artificial role-playing as a 'man,' how he talks and acts, corresponds to his role-playing in hiding his true nature from those around him - particularly women. After visiting Joyce at her house, she mistakes him for a paying customer as he does not let on he is a deputy at first. After being offered coffee and an opportunity to bed her, Ford decides that he'd 'let her ride' until he sees himself in her bedroom mirror. Upon seeing his reflection he changes his mind; finding a pistol in her dresser drawer he decides to confront her and reveals he is a deputy. She balks and abuses him, calling him a 'bastard' and a 'son-of-a-bitch.' This insult particularly riles Ford in this instance and later on in the novel, where it triggers a similar event with his long-time girl-friend and finance, wholesome Amy Stanton. ${ }^{11}$ The obvious affront to his mother resonates with Ford, who perhaps harbours bitter feelings of abandonment towards her. It is suggested later in the next chapter that she died giving birth to Lou: 'My mother was dead - had been dead since I was a baby" (19).

11. “'You son-of-a-bitch,' she said. 'You dirty, filthy bastard.'

'Wha-at?' I said. It was like getting a punch in the guts. Amy didn't go in for cussing. At least, I'd never heard her do much.” (P. 60) 
Alternatively, this particular insult is a threat to the idyllic, almost sacred, memory he might have of her. She continues her tirade of abuse, calling him a "son-of-a-bitch, bastard, pimp ..." Ford panics and tries to leave the house, thinking to himself via stream of consciousness:

I knew what was going to happen if I didn't get out, and I knew I couldn't let it happen. I might kill her. It might bring the sickness back. And even if I didn't and it didn't, I'd be washed up. She'd talk. She'd yell her head off. And people would start thinking, thinking and wondering about that time fifteen years ago. (11)

This particular passage from the second chapter also signals that the malady which ails Lou Ford has, either by himself or another (a doctor perhaps), been diagnosed medically. His 'sickness' has been dormant, but this woman has seen too much of the real person behind the law-man façade to brush it off. If she spoke of his behaviour, his past indiscretion ("fifteen years ago") would be connected to his present status and he could lose his job, but more importantly lose the security of the persona he has constructed for himself to hide behind.

Then Joyce slaps him. He snaps and subdues her with a punch, then strips her and binds her limbs with her own clothing before lashing her viciously with his belt until she loses consciousness. He starts to panic and manages to rouse her with coffee and a damp towel, all the while apologizing for his actions. She finally regains consciousness but instead of being angry with Ford, she kisses him and tells him not to apologize: “'don't talk.' She brushed her lips against mine. 'Don't say you're sorry.' She kissed me again. She began fumbling at my tie, my shirt; starting to undress me after I'd almost skinned her alive" (12-13). Apparently, she either has a sadomasochistic streak or she does what she feels she has to do, to stay alive under the circumstance. It is this acceptance of his violent behaviour that propels him forward into planning and committing more malicious acts:

I went back the next day and the day after that. I kept going back. And it was like a wind had been turned on a dying fire. I began needling people in that dead-pan way - needling 'em as a substitute for something else. I began thinking about settling scores with Chester Conway, of the Conway Construction Company.

I won't say that I hadn't thought of it before. Maybe I'd stayed on in Central City all these years, just in the hopes of getting even. But except for her I don't think I'd ever have done anything. She'd made the old fire burn again. She even showed me how to square with Conway. (13) 
Throughout the novel, Ford seems to see Chester Conway as a threat that needs to be removed from Central City. Conway is successful, powerful, an old friend of Ford's father and someone who Lou sees as a possible target. When Ford talks of 'settling scores' with Conway the reader is inclined to assume that he has a cause for revenge, but as the narrative unravels, it steadily becomes apparent that Conway is nothing more than a pawn in Ford's psychopathic game-plan. When Ford meets Joyce Lakeland and discovers that Chester's son is besotted with her, Ford sees his opportunity to exploit the unwitting trio. Chester approaches Ford to run Joyce out of town, obviously concerned that his son is mixing with the wrong type of woman and it is then that he commits the first in a series of violent assaults and murders.

In Chapter Three, Ford takes the reader on a tour of the house where he grew up and where he now lives. In the opening sequence, he parks his car in the garage and ruminates as he sits there. The garage is an old barn that is now used to house his vehicles - it still smells of 'the musty odours of old oats and hay and straw.' As he sits there he thinks back to when he and his brother, Mike, used to play in the barn:

We'd hung swings and acting bars from these rafters; and we'd made a swimming pool out of the horse trough. And up overhead in the loft, where the rats now scampered and scurried, Mike had found me with the little gi-_

A rat screamed suddenly on a high note.

I got out of the car and hurried out of the big sliding door of the barn, and into the backyard. I wondered if that was why I stayed here: To punish myself. (26)

Who is the 'little girl'? What happened? The reader can only surmise that, Ford had been caught with a child, dead or alive, and something untoward and traumatic had taken place. This insertion of an implied act of deviance from Ford's childhood, leaves the reader with more questions than answers. The metaphorical 'screaming' rat suggests that Ford is betraying himself by reliving the memory of a critical moment. In this instance, 'rat' is used both literally at first and then metaphorically after the slip where he nearly reveals the true nature of his deviant past. In noir literature, a rat is often used to refer to an informant who betrays information or trust and so it is employed here in the second instance. This use of metaphor and allusion also suggests that the narrative should be read both figuratively and literally. The barn can be read as a metaphorical embodiment symbolizing Ford's psychosis. The literal representation is shown to 
be the site where, it is suggested, Ford kills his first victim. The barn once housed horses; now they have effectively bolted, bringing to mind another clichéd phrase, 'closing the stable/barn door after the horse has bolted.' The horse in this instance is Ford's 'sickness' and the barn door has been metaphorically shut until the point where he resumes killing. The loft where the rats scurry and where the girl was killed, signifies Ford's troubled mind, as the rats similarly represent the memories that haunt him.

Most pulp readers of hard-boiled/noir fiction (1930-50s) would have been impervious to the metaphorical aspects of The Killer Inside Me and the frequent use of psychological concepts and allusion. The audience for these cheap magazines and paperbacks were largely comprised of working-class, non-academic readers. ${ }^{12}$ This in itself, is another distinguishing factor of Thompson's writing and, in particular, works within the serial killer fiction subgenre. Implied meaning, allusion and recourse to pseudo-scientific texts (psychiatric) all serve to heighten the reality of the serial killer character. Oftentimes, these types of characterizations can be seen to mimic case-histories, real-life crimes and popular psychological theories and concepts related to criminal psychopathology. For decades, many authors of works depicting 'psycho' killers perpetuated the myth that personalities were 'split' or divided, as was the common understanding at the time (clinically and publically), of 'schizoid' personality types who were deemed the perpetrators of this type of (serial) murder. ${ }^{13}$ This type of personality type would later be defined as having a 'multiple personality disorder,' or dissociative identity disorder as it is referred to today. As is often the case in less adept works of this type, fictional characterizations are constructed from a range of sources and as a result fail miserably in their depiction of real psychiatric disorders. Thompson, on the other hand, masterfully paints a portrait of a true violent

12. Smith, Erin, 'Dressed to Kill: Hard-Boiled Detective Fiction, Working Class Consumers, and Pulp Magazines." Colby Quarterly, Volume 36, no.1, March 2000, pp. 11-28 - "The readers of pulp magazines were widely held to be socially and economically marginal. They were working-class, young, poorly educated, and often immigrants. Although pulp publisher Harold Hersey claimed pulp readers came from all walks of life, he did concede that the majority were probably office or factory girls, soldiers, sailors, miners, dockworkers, ranchers, and others who worked with their hands. One survey by Popular Publications found that the typical reader of their pulps was "a young, married man in a manual job who had limited resources and lived in an industrial town."

13. Spanos, N. P. (1994), 'Multiple identity enactments and multiple personality disorder: A sociocognitive perspective.' Psychological Bulletin, 116, 143-165. 
psychopath or 'sociopath' (as Lou Ford would've been referred to in the 1950s) that conforms to common understanding of the disorder. ${ }^{14}$

Throughout the novel, Ford hints at his own psychopathology. He offers no clinical diagnosis for his 'sickness,' no factual account of what it is that is actually wrong with him, instead he lures the reader into believing that he does have a diagnosable mental affliction. Up until the final section of the novel, he offers the reader possible explanations for his violent deviant behaviour - all seemingly in an attempt to deflect blame. It is almost as though his narrative is a confession of sorts; a response to a question of his guilt, in this respect it mimics a criminal interview with the reader playing the role of the interrogator. With each supposed insight, he misinforms the reader who can only surmise as to the true nature of Ford's mental processes as another piece of the puzzle is laid to bare. He offers an explanation, towards the end of the narrative, about the essential nature of himself and effectively describes in essence the atypical character of the serial killer in modern fiction. The psychological characteristic is not that of the mad-man or the schizoid psychotic, it is the singular aspect of evil at play here He even goes so far as to quote from an actual psychological text book:

I've read a lot of stuff by a guy - name of Kraepelin, I believe - and I can't remember all of it, of course, or even the gist of all of it. But I remember the high points of some, the most important stuff, and I think it goes something like this:

'.. difficult to study because so seldom detected. The condition usually begins around the period of puberty, and is often precipitated by a severe shock. The subject suffers from strong feelings of guilt ... combined with a sense of frustration and persecution ... which increase as he grows older; yet there are rarely if ever any surface signs of ... disturbance. On the contrary, his behaviour appears to be entirely logical. He reasons soundly, even shrewdly. He is completely aware of what he does and why he does it...'

That was written about a disease, or a condition, rather, called dementia praecox. Schizophrenia, paranoid type. Acute, recurrent, advanced.

Incurable.

It was written, you might say, about-

But I reckon you know, don’t you? (218-9)

14. https://www.psychologytoday.com/basics/psychopathy - "The psychopath can appear normal, even charming. Underneath, he lacks conscience and empathy, making him manipulative, volatile and often (but by no means always) criminal." 
Once again, Thompson utilizes factual text to add to the hyper-real nature of his protagonist, which serves two main purposes. Firstly, it ties the narrative back to the earlier insights provided by Ford when he lists the psychological text-books that line his father's office book-shelves (Kraepelin is mentioned). Secondly, it reaffirms both his intellectual prowess and self-awareness and also questions the reader's understanding of Ford's psychopathology. Ford essentially mocks the reader and subtly implies that whatever the reader might think, the answer is less complicated and implicit than suggested. Reduced down to its essential qualities, the question Ford seems to ask of the reader is a judgement of good and evil. In some ways, the use of factual texts also signifies the intrusion of the author, in that by referencing said work/s, Thompson sign-posts further reading if one is prepared to extend themselves beyond the fictional narrative. If the reader does make the effort to read the abovementioned text, they are rewarded with a wealth of insights into both Ford's character and Thompson's research methodology and source of the protagonist's realistic portrayal of clinical psychopathology.

The Killer Inside Me is typical of modern serial killer fiction in that it uses and subverts traditional literary genre tropes and styles, depicts the character of the serial killer from an interior point of view characterised by a deviant psychopathy and cunning intellect, and uses graphically violent language and action to enhance the impact of the narrative in much the same way that tabloid publications report true-crime. By blending different types of genre discourse into a single narrative structure, the novel establishes itself as a unique hybrid that is hard to define. Is it a mystery novel? It does not seem to have a traditional suspenseful narrative like most mystery stories; for example, from the outset we are told by the protagonist narrator, that he has murdered someone. Is it a detective novel? Thompson effectively subverts this genre model by inserting the reader directly into the mind of the killer. Because of these amalgamations of genre tropes and styles, traditional reading and interpretation of the narrative is made more complex for the reader, who has to search amongst the layers of text for their own clues as to why Lou Ford is the way he is. Ultimately, the reader discovers that the narrative style is both, at times, literal and figurative in that the narrator is increasingly unreliable, reflecting his descent into a chaotic and bloody characterization of his own actions and persona.

Despite the first-person confessional narrative, at the conclusion of the novel the reader is still ignorant as to why Ford is the way he is. He dies in much the same way as he lives: violently and graphically. Yet it is a theatrical death that encompasses the whole style of the narrative in 
the final scene. Filled with ambiguity, allegory and violence, the passage is more like a staged performance as he dies dramatically in a hail of bullets and gun-smoke while simultaneously murdering the by-proxy object of his desires and the source of his 'sickness:'

And I sprang at her, I made for her just like they'd thought I would. Almost. And it was like I'd signaled, the way the smoke suddenly poured up through the floor. And the room exploded with shots and yells, and I seemed to explode with it, yelling and laughing and ... and ... Because they hadn't got the point. She'd got that between the ribs and the blade along with it. And they all lived happily ever after, I guess, and I guess - that's - all. (244)

As the story began, so it ends with a string of serialized paraphrases and clichés. The reader is left with a sense of emptiness as the dying narrator addresses us directly. His madness seems complete, his logic baffling and yet he asserts that life is as meaningless for him as it is for the reader. He lists all the characters that have either been murdered or affected by his actions, aligning himself with them as failed beings - imperfect humans: "All of us that started the game with a crooked cue, that wanted so much and got so little, that meant so good and did so bad. All us folks. Me and Joyce Lakeland, and Johnnie Pappas and Bob Maples and big ol' Elmer Conway and little ol' Amy Stanton" (244).

What might initially read as a conclusive ending, retrospectively seems ambiguous and poses more questions than it answers. The final two sentences divert the reader's gaze back toward themselves with a mantra-like repetition that seems to reinforce the ritualistic nature of the subject matter, as much as it suggests that we are all inherently evil: "All of us. All of us." 


\title{
Chapter Two: \\ James Ellroy's Killer on the Road - The First Postmodern Serial Killer Novel
}

\author{
"The psychopath may indeed be the perverted \\ and dangerous front-runner of a new kind of personality \\ which could become the central expression of human nature \\ before the twentieth century is over."
}

- Norman Mailer

Published in 1986 in the midst of America's much-hyped real and fictional serial killer epidemic,' Killer on the Road is James Ellroy's sixth novel. Among the milieu of fictional serial killer narratives available at the time, it stands out as a distinctive and important shift in focus and style, as well as putting forward a new kind of character - the homosexual serial murderer. In this novel, Ellroy delves into the phenomenon of motiveless serial murder from the perspective of the criminal antagonist, effectively transforming the traditional crime-fiction role of the villain as a secondary character, into one where the use of first-person narrative transcends literary convention by designating the role of protagonist to a murderer. Killer on the Road is a subversive journey through a hellish suburban America; from the prologue to the epilogue the reader is presented an interior world-view saturated with violence and nightmarish insights into the psychopathology of a disturbed killer. The metafictional aspects of the novel identify the 
work's status as much more than a traditional crime story: the use of ephemeral items such as journal entries, 'newspaper clippings', 'article extracts', and official (police, psychiatric, courts) documents makes the fiction seem more realistic. In this respect, Killer on the Road is a reactionary serial killer novel in the sense that the narrative is strongly self-aware of its place in the trajectory of other works of serial killer fiction and true crime journalism and seeks to create a point of difference in the unique combination of factual and fictional styles of writing and use of literary devices. It is also unique (for its time) in that the narrative effectively forces the reader to participate in, and confront, the relationship between fact and fiction by questioning the 'reality' of the serial killer and the reader's own response to that presentation.

Aside from the stylistic characteristics, it is a novel of its age in the immediacy, relevance and impact of its subject matter on a reading (American) public. At the time of writing, America was a country in the grip of a media-fed panic: serial killers and their crimes were one of the main news stories of the era. The 1980s -'90s have been referred to as the 'Golden Age' of serial murder and produced some of the most notorious serial killers. As Professor Harold Schechter was quoted as saying in a recent interview:

... the 1980s and '90s will be viewed as the "golden age" of the serial killer, not in the sense of glorification but rather their hold on the public's psyche. "That period witnessed the emergence of some of the most infamous serial killers in American history: Ted Bundy, John Wayne Gacy, Jeffrey Dahmer, Edmund Kemper, the Hillside Stranglers, Richard Ramirez, et al. It was also the era when the serial killer became the mythic monster that haunted the public imagination. (Prose ' $n$ Cons)

John Douglas, author and FBI serial murder 'profiler,' details in Mindhunter: Inside the FBI's Serial Crime Unit, how “virtually all serial killers come from dysfunctional backgrounds of sexual or physical abuse, drugs or alcoholism, or any of the related problems" (356). Like most of his factual serial killer counterparts, the central character of Martin Michael Plunkett is a lonely disturbed child who comes from a dysfunctional home. Plunkett's family are depicted as failed humans; his father is a paranoid drunk gambler and his mother has obvious mental health issues. At the age of seven years, Plunkett's parents' separation and Plunkett retreats into a disturbing fantasy world where he imagines violent and bizarre happenings to his classmates and those around him. The vivid fantasies or 'Brain Movies' (as they are referred to throughout the novel) become increasingly deviant and soon lead Plunkett to becoming a peeping Tom. After 
his father walks out on them, Plunkett devotes most of his spare time to voyeuristic activities, spying on neighbours and people engaged in sexual intercourse. As he gets older he exhibits more behaviour that eventually leads to his junior high-school teachers sending him to a school psychologist. With his prodigious intelligence Plunkett manipulates the psychologist into a fit of frustration, proving himself no match for Plunkett's mind games. Despite being flagged as 'disturbed' by the counsellor, he goes on to graduate and enters high school now equipped with the realization that he is somehow different from his peers. He endeavours to self-analyse his violent brain movies ${ }^{15}$ and thought processes and constructs an alter-ego built around one of his favourite comic-book characters, a super villain called 'Shroud Shifter,' a master criminal who was consumed with achieving the power of invisibility: "that goal drove him, pushed him beyond his existing gift of psychic invisibility - being able to fit in anyplace, anywhere, anytime. Being physically invisible would give him a carte blanche ticket to take over the world" (19).

As his idolization of Shroud Shifter or 'S.S.' increases, Plunkett decides to "make [him]self invisible" (19). He resolves to adopt the persona of an average 'normal' teenager in order to achieve a 'psychic' invisibility like S.S. but actually more in line with the image of the serial killer as 'everyman.' He realizes the importance and necessity of appearing non-descript so that he can hide his true nature. At this point in the story he has yet to kill and apart from his violent fantasises and deviant tendencies, Plunkett merely seems to want to blend in. He knows he needs to hide the part of him that others might see as different and aberrant.

After a confrontation with his mother after he attempts to create a costume out of her clothes, Plunkett is punished physically (she beats him) and emotionally. She imposes "six months of silence" as his punishment but instead of being hurt, Plunkett sees it as a "reprieve from my awful fears regarding the invisibility mission, and the opportunity to screen unlimited brain-movies" (21). During this period of self-imposed silence, Plunkett delves deep into his imagination and effectively constructs the fantasy world that would lead him into adulthood. Along with the fantasies grows a hatred towards his mother and to those around him, eventually culminating in the murder of his mother by way of swapping her medication with powerful

15. This technique of associating violent fantasies and situations with a cinematic experience, lends itself to interpreting the origins of the fetishistic serial killer's actions as being heavily influenced by visual media. This technique of associating violent fantasies and situations with a cinematic experience, lends itself to interpreting the origins of the fetishistic serial killer's actions as being heavily influenced by visual media. 
amphetamines. The drugs cause her to have a psychotic break-down and she kills herself, slitting her wrists in the bath. Plunkett calls the ambulance and police to report her 'suicide' and then sits by the bath lapping at her blood as he waits for them to arrive.

Following the death of his mother and because of his age he is placed in the foster care of a roguish LAPD officer, 'Uncle Walt Bochard,' who exists on the periphery of the police force. Plunkett immediately begins to manipulate Bochard when he finds out that he used to be a burglary detective and has an old set of lock picks and burglary tools that he gives to Martin:

That night I kept Bochard's monologues pinned to one subject: burglary. I did not have to feign rapt attention: this time it came of itself, as if the projector I used for brain-movies were on strike and I had found something better. I learned the practical uses of the beautiful brush-steeled tools; I picked up the rudiments of nullifying burglar-alarm wiring . . . I walked back to my room knowing that I now had the courage to do it. (27)

Plunket begins committing a series of fetishistic burglaries in which he breaks into women's houses after voyeuristically watching them engaged in intercourse, before stealing their valuables and killing any pets they might have. The act of burglary quickly becomes synonymous with a sexual act ${ }^{16}$ for Plunkett:

I stepped inside and eased the door shut, then stood perfectly still in the interior darkness, waiting for the shape of the front room to make itself known. My body from knees to pelvis tingled, and as I stood there thinking of Shroud Shifter, the feeling localized itself in my groin. (29)

In a parody of true events, Ellroy references the real life 'Tate/LaBianca Murders' (more commonly known as the 'Manson Murders') by having Plunkett comment on the ensuing difficulties created by the fear generated because of the crimes: 'the murder spelled panic and created a boom in all manner of security devices and services. Angelenos were buying guns and watchdogs, and were buttressing themselves against the still-uncaptured killers ... Burglary was

16. Many of Ellroy's works have a preoccupation with sex and the emotional and physical consequences of this basic human form of interaction. In relation to the many forms of sexual interaction and behaviours depicted in Killer on the Road, Ellroy's own words are useful in understanding Plunkett as the central character and the way in which he uses his sexuality as an extension of his violent desire for power: "in the hellish unreality of the psychopath, sex is a weapon." See Tucker, D. (1984) 'An Interview with James Ellroy’, in S. Powell (ed.) (2012) Conversations with James Ellroy, Jackson: University Press of Mississippi, pg. 6. 
getting to be a risky business" (49-50) Wary and stressed from having to stimulate himself via his fantasies, Plunkett waits for the public paranoia to die down and trolls Los Angeles for potential burglary victims. He overhears some 'hippies' talking about a guru called 'Charlie' who keeps a bevy of prostitutes and operates out of a club downtown. Plunkett decides to investigate, presumably the promise of both sex and money his reasoning behind his subsequent tracking down of the alleged guru and his 'targets.' He tracks two likely characters back to their apartment where he watches them have intercourse before listening to them talk about Charlie. That night he had a vivid dream where a "phantom named Charlie chased me, and I wanted to see why pretty young girls talked about him after they had made love with someone else, so I let myself be caught, screaming when I saw that Charlie's face was a mirror that reflected not my face, but a collage of butchered sex organs (pg. 58)"

Foreshadowing his inevitable capture and emphasizing his paranoid state he continues to describe the nightmare, going on to detail how figures from his past including his mother and guardian Walt Bochard taunted him cruelly as they morphed into jailers “...holding big metal keys that would unlock my voice, my brain, my memory." He heads back to the club the following day and tracks down the couple from the night before, this time he mistakenly identifies one of their companions as Manson and follows him and a women, breaking into their apartment where they are engaged in intercourse. In a comedic twist, the hippie couple overpower Plunkett and call the police, whereupon he is sentenced to a year in jail for breaking and entering. Using the time to increase his physical strength and increase his criminal prowess under the tutelage of senior criminals he ponders the almost mythological figure of Manson, aligning himself with the man and his crimes in his imagination. When he actually meets Manson after his arrest and incarceration, he is disgusted at the "far-gone psychotic" reality of the man. Plunkett engages Manson in a discussion about 'Helter Skelter' and then sets about belittling his philosophies until Manson becomes enraged. Feeling all the more powerful for his confrontation and figurative emasculation of Manson, Plunkett resolutely settles into the remainder of his sentence obsessively reading about other Los Angeles based serial killers in the prison library, studying the reasons for their captures and resolving to become the ultimate serial killer upon release.

After his release, Plunkett begins a series of dead-end jobs as his fantasy life begins to take over his sense of reality. Shroud Shifter begins to increasingly appear in a number of ultra- 
violent visions, prompting him to escalate his criminal activity along with violence. After killing a young couple who befriend him, Plunkett manages to cover up the crime by staging the murder as the work of drug dealers. After committing his first murders, Plunkett's fantasy world overpowers his reality and he travels cross-country on a killing spree in a specially outfitted van called the 'Death Mobile.' Arriving in Wisconsin, Plunkett kills a stranded motorist in a snowstorm and unwittingly puts himself in the path of police Sergeant Ross Anderson who reveals himself to be a serial killer responsible for a series of brutal rapes and murders of young women. Anderson and Plunkett strike up a bizarre relationship built on their mutual aptitude for violent murder. They go their separate ways while Anderson continues to use his position of authority to cover for Plunkett as his own murder spree escalates and attracts the attention of FBI agent Thomas Dusenberg who is charge of the squad tasked with identifying and apprehending the yet unknown, Anderson and Plunkett.

Eventually, after making a series of arrogant mistakes, Anderson is arrested for the 'Wisconsin Whipsaw' murders and quickly offers Plunkett's identity as the Shroud Shifter killer to his prosecutors, in an attempt to avoid the death penalty. Plunkett discovers that he is a fugitive and wanted for the serial murders after questioning a rookie police officer distributing 'wanted' posters. He wrongfully assumes that Anderson's family have identified him as the murderer and abruptly constructs a Shroud Shifter costume before driving to their home where he kills and the entire family in the bloodiest display of violence in Killer on the Road. Not only does he murder them all, he dismembers their limbs and displays them like pieces of a jigsaw puzzle, effectively deconstructing the idealized version of the white middle-class American family so that all remains is a violent scene of fragmentation and dissolute family values. After this final and brutal murder, Plunkett figuratively (and literally) disrobes from his costumed persona as he realizes that it could not have been Anderson's family who betrayed him as they didn't actually know his true identity, but Anderson himself. The fact that he kills an idealized version of an American family, completely enveloped in the fantasy character he has constructed for himself as a result of the dissolution of his own family, speaks volumes as to the true focus of his rage and violent origins. Perhaps this is as much an allegorical social commentary on the origins of violence (i.e. because of the disintegration of family structure and values) as it is a way to culminate the narrative experience. Immediately following the mass killing, he resigns himself to his fate and books in at a local boarding house under his real name and waits to be arrested. 
Long suffering lead FBI investigator Dusenberg arrests Plunkett, only to have him confess to crimes in states that don't fulfil the death penalty with an immunity agreement he will never be executed. Subsequently Plunkett is sentenced to a life in jail without the possibility of parole and housed in solitary confinement. After undergoing a psychotic breakdown where he becomes catatonic and reverts back to a mute state similar to his teenage years, he eventually begins to gather his thoughts and decides to seek publication of the memoir he has been working on while incarcerated (the 'memoir' is Killer on the Road). Meanwhile, Dusenberg is appalled that Plunkett seems to have benefitted from his predicament with the pending publication of his journals and turns to his family for comfort, only to discover that his wife has been unfaithful. It all proves too much for him and he contacts Plunkett's publisher, selling the rights to his own journal where he has been detailing his case work on the serial murders, examples of which are seen throughout the novel. After writing a will and leaving the money from the publishing deal to his children, he commits suicide. In a direct address to the reader, the novel concludes with Plunkett completing his memoirs and explicating that he has reached the end of his "warrior's noblesse oblige" (265). He goes on to provide the reader with reasons for his actions that are as much a declaration of ignorance and failed logic as they are specific summations of his behaviour: "[p]art of it was to kill my nightmares and staunch my awful rage, and part of it was for the sheer thrill and high-voltage sense of power that murder gave me. I cannot summarize my drives in any greater perspective than that" (266). He implies that he will once again retreat into his psyche in a form of symbolic physical suicide, free from all restraints and laws.

Ellroy's own preoccupation with death and crime is apparent and is central to understanding Killer on the Road as a Gothic noir novel, but it also reflects the reading public's fascination and consumption of graphic violent fiction and media accounts of 'real life' crimes. This ongoing obsession of the public with accounts of violence and criminal activity, is the logical reason why a market for serial killer novels like Killer on the Road exist and also the central basis for the author's preoccupation with the subject matter. In Conversations With James Ellroy, he recounts that:

[o]ne of the recurring themes in my books ... is to show the genealogies of violence. To attempt, as much as possible, to take the bad guys back to their childhood and follow their development up to the point where they start killing and maiming people. Hence, to explain those horrible, senseless and otherwise inexplicable acts ... Sex, death, horror, love - dying more often than it flourishes - these are the stuff of life and I don't want to flinch from 
them. I want to take them in their rawest, most complex forms, especially vis-à-vis the myriad of people involved in chains of violent events, and somehow make them cohesive in my mind for the reader. (25)

Despite Ellroy's disingenuous admission that the novel is 'the only book I ever wrote for the money, because I needed some dough' (Rich 2009), it is a disturbing and violent work that is interesting because of the way Ellroy presents and characterizes the distinctively American (in this case) serial killer. The fact that he took into consideration the huge public appeal of such a novel, reflects Ellroy's journalistic inclination in much the same way that American mass-media determines the appeal of certain content (i.e. serial killer reports) in order to maximize profits and readership by taking advantage of public fears. As Philip Simpson points out:

The mass-media purveyors of the serial killer legends in contemporary America respond quickly to their perceptions of the public's interests, fears, and concerns exactly because the media's economic survival is chained so thoroughly to the need to retain an audience that demands an extraordinary mix of the culturally forbidden and the socially conservative ... Media instruments react to any dramatic social phenomenon in a rumor cycle of everinflating narrative claims very recognizable to the folklorist. The net result is the creation of an overarching contemporary mythology where ... serial killers mutilate and devour the lost and unwary travelers in the American mythscape. (15-16)

Superficially, Killer on the Road is a narrative that can be read as a wholly fictional text, however due to the proliferation of ephemeral items such as realistic newspaper clippings, article extracts, journal entries and other official (police, psychiatric, courts) documents, it seems as if the author intends for the fiction to be aligned with its true-crime counterpart texts for a particular reason. In respect to the way the narrative is presented along with the first-person confessional narrative, the reader could be forgiven for thinking they were reading a non-fiction account of a serial murderer, but the question remains: why does Ellroy employ these techniques and tropes?

The deliberate use of pastiche and intertextual referencing to create this 'realistic vision' can be read as both a self-reflexive nod to the true-crime literature that informs and propels serial killer fiction and a symptomatic assimilation of the main tenets that define postmodern 
literature ${ }^{17}$ The use of ironic juxtapositions, interwoven styles (journalistic, tabloid, true-crime) and textual references combined with Ellroy's use of dark humour to address a serious 'real' subject within a complex fictional narrative, is indicative of a post-modern work that presents the reader with a hyper-real simulation of a factual topic, i.e. serial murder. As a result, the complex nature of the narrative construction and the juxtaposition of media-style reportage and popcultural references presents the reader with a book that is quite different from predecessors within the genre. As an immersive reading experience, Killer on the Road presents a narrative that encompasses nearly every aspect of the phenomenon of serial murder as represented across all written media. Ellroy directly addresses the reader in the opening chapter with a metafictionalized forewarning of sorts:

As this manuscript grows ... [t] here is a dynamic to the marketing of horror: serve it up with a hyperbolic flourish that distances even as it terrifies, then turn on the literal or figurative lights, inducing gratitude for the cessation of a nightmare that was too awful to be true in the first place. I will not observe that dynamic. I will not let you pity me. Charles Manson, babbling in his cell, deserves pity; Ted Bundy, protecting his innocence in order to attract correspondence with lonely women, deserves contempt. I deserve awe for standing inviolate at the end of the journey I am about to describe, and since the force of my nightmare prohibits surcease, you will give I to me. (5)

Aside from the obvious use of direct address to confront and shake the reader from any preconceived notions they might have about the novel, and to introduce the grandiose psychopathology of the central character - Martin Plunkett, this passage is as much a reference to the genre of serial killer fiction and the techniques previous authors have used to construct their work, as it is to the cultural context of actual serial murder and the continuance of the public's fascination with the subject.

17. For the purpose of this discussion I am using Brian McHale's definition of what constitutes a work of postmodern fiction: 'the dominant [thesis] of postmodernist fiction is ontological. That is, postmodernist fiction deploys strategies which engage and foreground questions like the ones Dick Higgins calls "post-cognitive": "Which world is this? What is to be done in it? Which of my selves is to do it?" Other typical postmodernist questions bear either on the ontology of the literary text itself or on the ontology of the world which it projects, for instance: What is a world?; What kinds of world are there, how are they constituted, and how do they differ?; What happens when different kinds of world are placed in confrontation, or when boundaries between worlds are violated?; What is the mode of existence of a text, and what is the mode of existence of the world (or worlds) it projects?; How is a projected world structured? And so on." From Postmodernist Fiction, Routledge, 2003. Pg. 10. 
In regard to Ellroy's own blasé reasoning (i.e. 'for the money), the popularity of the genre and the public's morbid fascination with the subject, it would be easy to dismiss Killer on the Road as just another serial killer novel in a long line of similar works cashing in on a topical phenomenon. Instead, a critical interpretation of the novel reveals many aspects that cite contemporary (1980s America) cultural and social issues and trends in literary genre movements. The juxtaposition of faux 'real' text alongside fictional narrative signals a particular method of interpretation is required to fully understand the work in the context of both the age and the tradition of the genre in which it was written. When interviewed, Ellroy reveals a more interesting reason for creating worlds and characters that straddle the line between fiction and nonfiction as he asks the interviewer to "consider the fact that crime in America is rapidly escalating, assuming as many bizarre forms as there are lunatic perpetrators to give them form. The reader out to sate his dark curiosity and inform himself on the violence that surrounds him will want a hero, or antihero, who meets the requirements of a realistic vision." 18

Killer on the Road puts forward a darkly ironic portrayal of the serial killer as hero. Martin Plunkett identifies with and models his serial killer persona on a comic book character called 'Shroud Shifter." Ellroy highlights the absurdity and pop-cultural nature of the character by associating and amalgamating a graphic fiction genre-type (comic books) with the popular (judging by media and public interest) cultural figure of the criminal super-villain - the serial killer, as reported by news media and true crime non-fiction works. The depiction of Martin Plunkett's psychopathology as represented by his alter-ego (Shroud Shifter) is ironic, in that while Ellroy seems to employ various tropes and associations drawn from pop-culture in order to make the character more believably human and real (presumably), he effectively reduces the character to a bastardized version of the serial killer and his killings become almost comedic and hyperbolically absurd. Whether or not Ellroy intended this to be the case, the character of Martin Plunkett the serial killer is a hybrid amalgam of both real-world non-fiction profiles and popcultural constructionism. If it weren't for the gruesome subject matter and the sheer horror of the work as a whole, Killer on the Road would be farcical to readers of thriller/crime fiction novels because of the absurdist nature of the narrator. The switching of traditional crime fiction roles is

18. Tucker, D. (1984) ‘An Interview with James Ellroy’, in S. Powell (ed.) (2012) Conversations with James Ellroy, Jackson: University Press of Mississippi, pg. 9. 
also apparent via Plunkett's obsession with super heroes and role-modelling behaviour (re. the idealized authority figure of serial killer cop, Ross Anderson). Traditionally, crime and detective fiction have emphasized the heroic qualities of the lead protagonist - the detective or lead investigator. Ellroy flips this trope by aligning Plunkett with a steady stream of heroic (but cartoonish) characterizations. As Christiana Gregoriou points out:

... the discourse surrounding our fictional serial killers in particular elevates them to the status of contemporary avengers or even heroes, much like hero detectives in modern crime fiction, and actual fire-fighters in real life. Besides, they can be said to rid us from those we are not meant to value (i.e. prostitutes, criminals, gay men), and help us honour the ones we are meant to indeed value (i.e. attractive women, young children, parents). Even with this not being the sort of glamour with which we want to view real life serial killers, the myth surrounding them does exist and, in that respect at least, the myth is, indeed, real.

(Language, Ideology, and Identity in Serial Killer Narratives, 175-6)

This creation of myth ala the heroic serial killer character of Plunkett can never really be taken seriously because of Ellroy's use of irony in the allegorical depiction of the disintegration of the killer's fantasy world. For it is only when Plunkett assumes the physical 'real' garb of Shroud Shifter and wholly adopts the alter-ego in the form that serves as both a mythological substitute for his ideal self and a representation of the other he wishes to become, does the truth of his character finally reveal itself. For Plunkett, SS is an imaginary vessel by which he processes and houses the deviant desires and urges that drive him to kill. The persona is a figurative mask that he wears to usher his fantasizes out into the world around him, effectively transforming the reality of his crimes into fictionalized stories or 'brain movies' that feed into the construction of his (Plunkett's) own identity and mythology. Until he meets fellow serial killer and cop Lieutenant Ross Anderson, and becomes infatuated with him, SS serves Plunkett as his raison d'être - the most influential figure in his life. After killing a stranded motorist in a snow storm, Plunkett is stopped at a police road-block and arrested as a possible suspect in another spate of serial murders. Ignorant of the murder he has just committed, the police process him at a local police station and clear him of any involvement in the serial murders they are investigating, the body of the man Plunkett shot still not discovered in the storm. Enter Anderson who quietly reveals to Plunkett that he knows he murdered the man, producing the gun and stolen wallet that he had found hidden in the 'Death Mobile.' Plunkett begins to panic but realizes that Anderson is 
of a similar ilk as the cop secrets the evidence and directs him to stay overnight in a hotel room that turns out to be Anderson's own lodgings.

After telling Plunkett that he actually saw him murder the man, Anderson goes on to show him Polaroid photographs of his own series of victims and they share stories about their respective crimes. After a brief sexually-charged night together, Anderson bids Plunkett farewell and lets him know that "[y]our stuff is safe with me. I'll never rat you off, but I may need you someday and the evidence is insurance" (147). They kiss and go their separate ways; as a result of their liaison and the uncovering by Anderson that Martin is a serial killer, Plunkett's fantasy world begins to merge with reality and Shroud Shifter is banished to the past. As he travels cross-country, Plunkett's thoughts become saturated with the over-powering presence of Anderson "Ross loomed all around me - faceless as an advisor, but savagely beautiful and dangerous when I didn't listen to him" (173). If Plunkett's sexuality had been in question prior to this event, it is now apparent that homosexuality is a self-identifying aspect of his character as it is presented as the 'truth' of his self.

The fact that Anderson kills and rapes females gives his character an air of unreliability and ambiguousness due to his homosexual attraction to Plunkett. When he initially tells Plunkett about his crimes, Anderson gives his reasons for selecting female victims, stating "I've always dug foxy young brunettes ..." (46). Plunkett asks him if he could change his modus operandi (M.O.) but Anderson disregards the implications of his question and continues talking about killing females, rendering his sexual orientation vague and ambivalent. Plunkett is forced to confront his own sexuality as he realizes that his feelings may never be reciprocated in the same way. From this point forward, Plunkett's grasp on reality paradoxically disintegrates as he searches for a new victim that looks like himself in order to kill and assume a new identity. His fantasy world and his reality have switched places with the intrusion of the 'real' now more prevalent in his thoughts and experience. He desperately searches for his next victim, “...tearing cross-country in flight from real sex [italics mine], seeking the perfect non-Martin to become, burning like an ant caught in sunlight through a magnifying glass held by a sadistic child. Burning my way back to my own childhood" (171). As he travels he encounters many potential victims, most of which prove unsuitable as deemed by Anderson who is now firmly entrenched in Plunkett's psyche as his alter-ego: "Ross, faceless, only a voice, kept me from wasting them, kept the idea of a new identity in my mind. In the counsellor role that Shroud Shifter used to 
play, he told me to take my time and eschew murder until I found a perfectly expendable man to become, a man who looked exactly like me and who would never be missed. Knowing that Ross [Anderson] would remain sexless only if I obeyed him. I waited" (173-4).

This passage suggests that if Plunkett obeys Anderson the alter-ego, then the real Anderson would be subsumed by the fantasy, leaving any chance of an actual relationship an unconsummated dream. And so Plunkett waits, feeding off the fantasy of Anderson in lieu of the real thing. He yearns for a chance at a real relationship with the only person he has found to be of a similar nature to himself; that is, a serial killer. The fact that Anderson is also a cop, accentuates the ideal by aligning him with the only other father-figure in Plunkett's life LAPD, police officer 'Uncle Walt Bochard.' The uniform and the wielding of power and influence, combined with his prowess as a serial killer, homosexual tendencies and his apparent impunity from the law by operating from within, makes Anderson larger-than-life and a perfect role-model and potential life-mate for Plunkett. Despite his ideal candidacy as a partner, as long as Anderson remains separate from Plunkett, he can only exist temporally in his Martin's mind and fantasies.

Ellroy's conception of Plunkett as the quintessential characterization of the modern American serial killer is both an indictment of place and a representation of the self within that context. Plunkett is the ultimate figure of the outsider loner - the solitary individual 'self' in a state of perpetual quest and existential angst in search of the elusive 'other. In Plunkett's case, the 'other' is a transgressive and symbolic objectification of both victim and lover, in that it is through these allegorical human simulations and interactions that he seeks the unattainable missing 'thing' that is his own (normal) identity. Using fragments of his cultural surroundings, e.g. comic cartoon characters, newspaper clippings, neighbourhood environs and characters, life experiences and events etc., Plunkett constructs a mutated self for his persona, much like the allegorical monster in Frankenstein by Mary Shelly. Plunkett's vacuous character acts as a symbolic embodiment of American culture, particularly those aspects of that culture that generate violence, crime and anti-authoritarian behaviours. While he represents the predominantly-white male American individual, it is a representation that underscores an existential crisis of the self and, by association and placement, a mutation of values, experience and beliefs that threaten the very world in which he inhabits (namely, America). While this interpretation may seem to indicate an authorial agenda present in the narrative, the figure of the fictional serial killer is such a slippery literary device that it lends itself to multiple critiques of 
different persuasion. Ellroy himself indicates that the worlds and characters he creates are simply exercises in contemplation and essentially an exploration of the dark-side of the human condition. In an interview with Duane Tucker he states:

I'm interested in people who tread outside the bounds of conventional morality; displaced romantics ill at ease in the 1980s; people who have rejected a goodly amount of life's amenities in order to dance to the music in their own heads. The price of that music is very, very high, and no one has ever gotten away without paying. Both cops and killers fall into that category, to varying degrees, walking the sharpest of edges between their own music and the conventional music that surrounds them. Think of the potential conflicts. A modern-day policeman, equipped with technology and a pitch-black scepticism, a man who would have been a good medieval warrior, meets a psychopathic killer who manoeuvres in the real world yet is fuelled by an indecipherable, symbolic language - in other words, pure insanity... think of the opportunities to explore psyches and moral codes under incredible duress. Think of how precious physical sacrifice and human love stand out when juxtaposed against the severely contained universe I just described.

(Conversations With James Ellroy, 5-6)

Perhaps more telling (and from the same interview), in response to Tucker's suggestion that the fictional worlds that his characters inhabit are 'extreme,' Ellroy reveals that: "Extreme only because its facts are made explicit. Beyond that, highly prosaic, even vulgar. Eschewing the tabloids completely, pick up a copy of any newspaper. You'll find elliptically worded accounts of psychopathic slaughter in most of them." (Conversations...6)

Because of its complexity and slipperiness in terms of style and (genre) definition, any interpretation of Killer on the Road is prone to subjective bias and political or theory-based leanings. For the average reader a more simplistic approach could be considered in order to understand the ontological nature of the work. The early description of Plunkett's fantasies as 'Brain Movies' provides the reader with a method of interpretation, suggesting that the narrative can be read in a cinematic fashion - similar to watching a movie - as opposed to a more complex and deep reading based on the juxtaposition of ephemeral documentation throughout the work in the form of tabloid/journalistic reports and media clippings which heighten the 'reality' of the killer and his murders. Similarly, in much the same way as Ellroy pioneered (in the genre of serial killer fiction) the use of these devices in Killer on the Road, contemporary fictional renderings of serial killers now often employ these devices as a matter of course to heighten the impact on the reader, but also as a means of validating the depictions as legitimate portrayals of 
true-to-life serial killers. Glenn D'Cruz suggests in his essay, 'Representing the Serial Killer: 'Postmodern' Pedagogy in Performance Studies,' that these devices are used to 'explain' the enigmatic nature of serial killers, pointing out that:

These [fictional] voices with respect to "serial killer" texts are, almost invariably composed of fragments of discourse drawn from highly specific fields of knowledge - criminology, psychoanalysis, forensic science and so on and are usually deployed in the service of the detective/ protagonist's quest to solve the enigma of the serial killer: What are the psychological motivations? What traces are left behind? How does the detective read the victims' bodies? The "factual," "real" knowledges of criminology and psychoanalysis attempt an explanation. (323-332)

The fact that Ellroy uses these types of literary devices to enhance the 'reality' of the work also points to another aspect that is perhaps more pertinent to the way we should read the novel. Because we already know who the killer is from the onset, and in light of the way Ellroy structures the narrative around fragments of realistic documented evidence of his (Plunkett's) crimes, the question begs to be asked: 'what is the point of constructing the novel in his way?' There are a number of reasons why Ellroy might have done this; he may have simply wanted to make the narrative as realistic as possible; to write a serial killer novel that differed from others already published, or he may have used these devices purely for effect. As researcher and author Steven Powell suggests in James Ellroy: Demon Dog of Crime Fiction:

Ellroy taps into the public's combined fascination with and repulsion from serial killers while also noting their status as a commodity in a consumerist, tabloid-obsessed society. Ellroy paints himself as a form of circus ringmaster to a public that hungrily devours information about serial killers. He directly addresses his readers as voyeurs, wanting to indulge some dark fantasy but with the 'morally superior' reassurance that they are not participating. (36)

The positioning of the novel as crime fiction owes much to the tradition in which it follows but also to the difficulty of determining under what genre it should be shelved. 'Crime fiction' tends to be an umbrella term for those works pertaining to the depiction of all things 
crime related of a fiction nature. ${ }^{19}$ It is not a mystery or a traditional detective story in that we already know who the killer is and therefore the 'mystery' has already been solved by the author (and the reader); it is not an a-typical thriller or police procedural because it does not employ conventional narrative structure (i.e. other than a beginning, middle and an end there is no clear action or main suspenseful element and plot resolution like most thrillers and police-procedurals typify). Killer on the Road, in regard to the above-mentioned questions posed and the difficulty of classification in terms of genre-type, takes on a postmodern complexity that threatens to undermine serious literary interpretation because of these factors. Because it is hard to define and refuses to conform to literary conventions it would be easy to disregard the novel as inadequate or failed in some respects. At first reading the purpose of the work remains elusive and it is not until the novel is read contextually and allegorically, in terms of both the fictional narrative and the emphasis on the facsimile-style 'true' documentation throughout the work, that the work's message can be revealed.

It is my contention, that because of the use of first-person narration, stream of consciousness, ontological postmodern concerns and conceits that deal with surfaces, fragmentation and subjectivism, these factors qualify Killer on the Road as a work of literary serial killer fiction. Like the other narratives discussed in this essay that can be classified in this category, the characteristic technical innovation, sociological and psychological hermeneutic influences and self-consciousness text, are evident in Ellroy's narrative. While the text is explicit in the depiction of the murderer, the crimes, the social and cultural contexts and the violence, it is left to the reader to gauge their own responses to what is presented to them and, by proxy, the implications of those inferences in terms of cultural/social and individual significance. As Christinia Gregoriou suggests:

Our serial killer narratives, in the very end, reflect our societal values ..., our beliefs with respect to the law, religion and sexuality (prostitutes and gay men are judged by some minority - i.e. religious - groups as being 'more favorable' victims than non-prostitutes and straight men), our morals, ethics and political opinions (with respect to the acceptability of

19. "Crime fiction is the literary genre that fictionalizes crimes, their detection, criminals, and their motives. It is usually distinguished from mainstream fiction and other genres such as historical fiction or science fiction, but the boundaries are indistinct. Crime fiction has multiple subgenres, including detective fiction (such as the whodunit), courtroom drama, hard-boiled fiction and legal thrillers. Suspense and mystery are key elements that are nearly ubiquitous to the genre." Wikipediahttps://en.wikipedia.org/wiki/Crime_fiction 
capital punishment, for instance), not to mention our perceptions on matters of class (reflected in the readership of target audiences of given newspapers, for instance). 


\section{CHAPTER THREE: BRETT EASTON ELLIS'S AMERICAN PSYCHO: SURFACES AND THE COMMODIFICATION OF SERIAL MURDER}

'He who makes a beast of himself gets rid of the pain of being a man'

- Dr Samuel Johnson

Of all the post-modern fictional serial-killer narratives discussed in this essay, none has generated more controversy, or is more graphically explicit, than Brett Easton Ellis's American Psycho. The two main threads of serious literary criticism directed at American Psycho stem from feminist theoretical perspectives and postmodern critical theory which examines the novel within cultural and social contexts. Since its release, American Psycho has polarized critics and readers alike, due largely to the actions of its central character, Patrick Bateman, who exhibits extreme levels of behaviour (dependent on circumstance) as his corporate identity is consumed by his violent fantasies. In his portrayal of affluence and corporate hierarchy he excels at 
incorporating all the trappings of his high-income lifestyle into his persona and material possessions - he wears the best clothing brands, shops at the most expensive stores, flaunts the most ornate business card and is obsessed with money and luxury items. As the story unwinds, his narcissistic behaviour in the 'real' world escalates as he pursues gratification for his repellent and sexually violent fantasies, revealing him to be nothing less than a psychopath who may or may not be a serial killer.

This confusion as to his true identity is a recurring motif throughout the novel and one which leads the reader to question the validity of Bateman's claims and his reliability as a narrator at the novel's conclusion. Like a post-modern version of the Roman emperor Caligula, no perversion is apparently too taboo for Bateman, no experience too horrific - everything is merely a sensation that serves to satiate his lust for power and his escalating sense of sensory deprivation. Espousing conservative values and a right-wing commitment to enforce his twisted idealism under the guise of a 'might is right' philosophy, Bateman denigrates his victims with recourse to their place on a hierarchical scale of economic value. This characterisation as an allegorical figure who represents American capitalist ideals and conservative freedoms, while also being prone to pornographic fantasises and psychopathic behaviours, suggests that Bateman's employment of violence is an extension of his 'right' to defend his beliefs and ideals, no matter how shallow, bigoted or misogynistic they may be. It is almost as though his whole psychopathic philosophy hinges on his extreme interpretation of the American constitution. His ultra-violent actions, merely an interpretation of his patriotic right to express himself freely - i.e. 'freedom of expression' in a mode of conservative self-righteousness and psychopathic indifference. This self-determining factor is as much a reflection of American 'democratic' capitalism embodied in the character of Patrick Bateman, as it is an indicator of Ellis's transgressive methodology that he employs to extend the boundaries of 'acceptable' literary fiction. Ellis not only holds up a mirror to capitalist consumerism and its failings in American Psycho, he also interprets the serial killer through the lens of literary fiction and its various tropes and genre-specific conventions.

For Patrick Bateman is not a typical variation of other fictional serial killer characters that have previously been portrayed in narrative form. His dialogue and actions are simultaneously, and hyperbolically, both vapid and violent; his character profile borders on caricature with a physicality and invincibility aligned to that all-American cartoon hero by name - the 'dark 
knight,' 'Batman.' Tempered with a Nietzschean 'will to power' and a propensity for hedonistic behaviour, Bateman is a philosophical hybrid whose existential angst cannot penetrate the surface of absurdity that defines this novel. His recourse to sadistic sexual violence signals an aesthetic mandate employed by Ellis that is the central source of the majority of the criticism directed at the novel and the author. The four main scenes in the novel detailing the torture, sexual violation and violent murder of women are more hyperbolic and visually detailed than any of the other apparent ${ }^{20}$ murders throughout the story. Yet, as brutal and as repellent as they are, the descriptions are no more lurid or gratuitous than true-crime case studies published on a regular basis in factual books, magazines and television documentaries. However, there is a discernible aesthetic quality to the graphic descriptions, that is both confusing and disarming in terms of the underlying raison d'être behind the inclusion. The deliberateness of these particular passages, which did in fact generate a strong critical response, signal a possible authorial pretence in the knowledge they would likely cause a provocation of sorts. In her article, 'American Psychos: The Serial Killer in Contemporary Fiction,' Jane Caputi, one of the most outspoken and articulate feminist critics of sexual violence against women present in media representations, has this to say about the impact it had on herself and the

... National Organisation of Women who cautioned that the graphic depictions of lethal misogyny might prove inspirational to some readers. Reading it, I was at first surprised to find that Ellis in some ways refuses the standard mythicization of the serial killer and actually deconstructs many aspects of that lore. Typically the serial killer is presented as the ultimately mysterious psychopath, adamantly undetermined by his culture, his monstrosity, if anything, the result of early abuse by a Bitch mother ... the hero of the well-titled American Psycho is Patrick Bateman, a man who epitomizes the "best" of American society. He is masculine, homophobic, white, rich, profoundly materialistic, "pornacious" (that is, salaciously and insatiably interested in pornography)... The novel thus offers an accurate, if partial, critique of the serial killer as the product of U.S. American consumer

20. I use the word 'apparent' here because the murders are not definitely portrayed as true occurrences within the novel; instead, Bateman's unreliable narration leaves the reader questioning the truth of the story (within a fictional context) and, at the culmination of the narrative, in doubt as to whether the whole tale was no more than a fantastical journey through the mind and perversions of the lead character. The epigraph quoted from Dante's Inferno (referencing the gates of hell) at the onset of the narrative: "Abandon all hope ye who enter here" written in spray-paint on a bank wall, becomes most relevant at this point in the novel (i.e. the ending) when the reader is led to question their perception of the novel and the events therein, as either fantasy of fictional fact. Another sign on a wall at the end of the narrative, concludes the story with the sentence: "this is not an exit," effectively looping the ending with the beginning (i.e. exit and entrance) and indicating that the novel must be read as a labyrinthine exercise rather than as a 'straight' narrative. In this respect, nothing is as it seems. 
ideologies and class hierarchies. Yet, at the same time, the novel ignores any gender analysis of the origins or behaviors of the serial killer and becomes itself a work of femicidal pornography ... [which] represented a significant symbolic assault on American women. (103-4)

Caputi astutely points out the difference between depictions of male-on-male violence and male-on-female violence, as carried out by Bateman in the narrative. She notes that when males are murdered, the action is non-sexual and "relatively short," but when females are slain the narrative is much more detailed in the way "sequences are extensive . . f frequently follow[ing] upon several pages of basic sadomasochistic sexual description clearly aimed at arousing the reader” ('American Psychos...,'103). Caputi goes on to assert that prior to these scenes of violence towards women, the reader is deliberately "sexually primed" with erotically charged and pornographic action, immediately followed by scenes of "unmatched violence wherein the women are tortured and killed in ornate and highly sexualised ways." ("American Psychos...,'104). This fact that the violence perpetrated upon female victims is different in quality and quantity to the violence perpetrated upon males is a disturbing aspect of the narrative that cannot be denied. Could its inclusion be simply a deliberate representation of violence in American society (particularly misogynistic violence), or a provocation to censorship and the treatment of taboo subjects? An attempt at shocking avant-garde content that disrupts genre convention and expectations? Or merely, violence-for-violence-sakes? My opinion is that the depiction of this type of overt violence is a combination of these possible reasons, combined with a parodic recourse to tabloid-style reporting of true-crime case studies.

Whatever Ellis's reasoning for his graphic use of violence, the subversive and controversial nature of American Psycho inevitably prompts discussion that questions the novel as a cultural artefact and the place of the novel, in general, as a vehicle for the critique of society. In this respect, American Psycho is a postmodern parody with Juvenalian overtones that puts forth a scatological representation of the worst American excesses imaginable, through the lens of an unreliable narrator who happens to be a white American male with extreme misogynistic tendencies. The combination of capitalist materialism and the negative results of that idealism, are perfectly embodied in the character of Patrick Bateman, the ultimate 'warts-and-all' symbol of white, male, American values. In this respect, American Psycho is a distillation of distinctly American ideals. The postmodern essence of the project is reflected in the dichotomous parallels 
drawn between the 'American Dream' and the American nightmare. This juxtaposition of optimism and nihilism parallels the doubling of identities that Bateman struggles with - both seem invariably entwined and, once again, regulated by surface constraints dependent on varying degrees of depth. Typically, the manic heights of positive pop-culture reverence and capitalist excesses throughout the narrative are outweighed by the more condensed forays into the depths of depravity and violence.

American Psycho is a postmodern murder narrative where pop-culture is elevated to highart, human relationships are means to an end, and where 'playing the game' is more valued than any real intellectual prowess. It is this shallowness that emphasizes the narcissistic nature of superficial materialism which is an all-consuming aspect of the characters and a main narrative motif. Bateman is the only character who seems to have intellectual leanings but (despite all his posturing and monotonous diatribes about the value of 80's pop music), even then his pretentiousness ensures that his musings never really penetrate beneath surface-level. This vacuity is symptomatic not only of the characters' alignment with generational concerns of wealth, status and pleasure-seeking, much like their real-life counterparts, but it is also indicative of the novel's standing as a postmodern work of literature. Indeed, the fact that American Psycho is the antithesis of modernist literature (in its use of fragmentation, paradox and an unreliable narrator) also accentuates the parodic nature of the work and its firm standing as a representative narrative of the culture from whence it came. It is very much an artefact of its era; the subject matter itself bundles two of the main cultural and political concerns from the 1980s: the economic collapse of the American stock-market and resulting recession and the scourge of serial murder that, according to the American media, was so prevalent during that period. As academic critic, David Schmid points out, “[t]he serial killer became a dominant media figure [in the 1980s] not only because he personified the tabloid sensibility (all scandal, all the time) but also because he exemplified other important features of how the contemporary American mass media represent crime" (Natural Born Celebrities, 14).

With the massive interest and notoriety garnered by the controversial publication and subsequent media-storm, American Psycho proved that the transgressive nature of serial-killer fiction was a useful allegorical and literary mode of delivering difficult subject matter to audiences more akin to perusing works of 'high culture.' The point of transition, which created this opportunity for Ellis's hugely successful integration of high and low (pop) culture in the 
story of American Psycho, was a work that stands as one of the greatest examples of main-stream serial-killer fiction, The Silence of The Lambs by Thomas Harris. Harris's narrative employs the traditional style of mystery-thriller fiction and an authoritative and realistic portrayal of factual law enforcement procedures and serial-homicide case studies. The Silence of the Lambs and the other works in the 'Hannibal Lecter' trilogy (Red Dragon and Hannibal) proved so popular with readers and critics alike that the marketability and viability of well-written fictional serial-killer narratives was firmly established. The huge public interest in the social phenomena of serialmurder during the time of publication (both factual and fictional) combined with the quality of the writing, ensured that the medium and subject matter were no longer relegated to the confines of the pulp-era, but were perhaps seen as more adaptable and useful as a literary mode or device that could be used across most fictional genres, including that of literary fiction.

Differing from previous post-war works of fictional serial-killer narratives, American Psycho deviates from the usual literary conventions of plot and characterisation to deliver an unusual hybrid of a novel that seems deliberately obtuse and, at face-value, rather pointless. The use of plot devices and other traditionally employed literary modes, carried over from the mystery thrillers and dime-store pulp novels in previous works of serial-killer fiction, appear non-existent. The prevalence of lists, pop-culture references, fragmentation and paradoxical observations, all juxtaposed with an unreliable first-person narrator and an apparently deliberate eschewment of meaning, are implicit characteristics of post-modern literature and integral facets of American Psycho. This is a new type of fictional serial-killer story, written under the guise of 'literary fiction' by a noted proponent of the craft.

American Psycho manages to stretch the genre boundaries of fiction that thematically deals with serial murder. As part of the serial killer fiction genre, the novel takes its place as a chronological exemplar of trends in American cultural history that are distinct to the era in which they are produced, while also serving as a logical extension of earlier literary trends that began with the publication of seminal works such as Robert Bloch's Psycho and Jim Thompson's The Killer Inside Me. As part of a series of works that sought to portray the inner psychological processes that create abhorrent human behaviour, the serial killer, American Psycho takes the 'realism' of earlier genre examples and combines it with an obvious satirical mandate that renders it a pastiche of literary mode as well as cultural critique. The deliberate and hyperbolic rendering of misogynistic sexual violence, combined with the use of (albeit, dark) humour, irony, 
hyperbole and ridicule, flags the novel as satirically transgressive. The fact that the violence, especially the violence towards the women (other than Bateman's girlfriend), is portrayed in such an exaggerated fashion and with such inventiveness, emphasises Ellis's agenda in the use of such narrative content and form. The question must be asked: why would he depict violence in such a manner? Ellis himself offers an explanation for the source of his graphic descriptions in an interview with the Paris Review:

When I wrote those scenes I was thinking about a lot of things - the EC comics of my youth, like Tales from the Crypt and The Vault of Horror, and various slasher movies I saw as a kid and a lot of horror fiction I'd read. Then it was turned up a notch just by being in Patrick Bateman's mind-set for three years and by imagining how a psychotic who works on Wall Street during the day might describe these things. A lot of those details I couldn't make up, so there was some kind of FBI textbook I got hold of that went into very graphic detail about various serial killers and how they would torture people. But ultimately I winged it, more or less. It's fiction.

In Julian Murphet's Bret Easton Ellis's American Psycho: A Reader's Guide, Ellis admits lying in interviews, recants his initial denial of any autobiographical content in American Psycho, and states that he has actively coveted his homosexuality. Murphet reiterates this by suggesting Ellis has garnered a reputation amongst critics for being notoriously unreliable in interviews and articles (especially in relation to American Psycho), so while his reasoning may be questionable it still provides a framework for further discussion (11-22). The fact that he is seemingly as unreliable as Bateman is as narrator of the novel, draws interesting parallels. There are many possible answers as to why Ellis, or any other author who writes in this genre, uses graphic violence against women in particular as part of their narrative. In American Psycho it inevitably creates a 'shock' value for the reader, as well as signalling events in the narrative that deviate from the norm and link together throughout the novel. The lack of subtlety or discretion in the descriptions reveal a journalistic aspect to Ellis's characterisation of Bateman. When compared with other dialogue and descriptive techniques used in the narrative, the violent scenes stand out as being very mechanical and rendered in such a clinical way that they could well have been clipped from any number of factual news reports dealing with serial murder. The fact that Ellis's descriptions are so varied in terms of the types of violence perpetrated on the female victims and the use of different methods of killing, murder weapons and victim typology, shows that the author's understanding of the subject matter (i.e. serial murder) is either haphazard or 
intentionally variable, purely for literary effect. Indeed, Ellis's depiction of Bateman as a serial killer stands out amongst fictional examples as being almost antithetical in any resemblance to factual serial killer profiles.

As an example of serial killer fiction, American Psycho is one of the few narratives of this type where the serial killer is not portrayed as the 'man-next-door' archetype, or the 'everyman' figure of the average male. Bateman is far from the seemingly invisible killer who, when revealed, is all the more shocking because they are merely 'ordinary' and incredibly average human beings on the surface. As journalist, Joel Achenbach, suggests in his article, 'Serial Killers: Shattering the Myth:'

Bateman is not merely fictional, he's totally improbable. Serial killers are invariably professional failures -- even the ones like Ted Bundy and Christopher Wilder whose few minor achievements were exaggerated by the news media. No known serial killer in America has ever been remotely as well-educated, affluent and successful as Ellis's murderer.

Despite this distance between Bateman's implausible portrayal of a psychopathic serial killer and the reality of real-life serial killer case studies, he does possess some of those typical characteristics attributed to his factual counterpart; at least in his own mind. Perhaps the closest proximity to the reality of the psychopath is in the behaviour he exhibits, particularly when he is not committing heinous acts of violence. Notably, he feels invisible to those around him and seeks to distinguish himself as different to everyone else while having no actual empathy for anyone. He seems stuck in a paradoxical quagmire, in that he wants everyone to see his power and the lengths he will go to control his world (including his murders) and yet he aches to conform and attain the prestige of corporate success. As it becomes for the reader, is a neverending battle between reality and fantasy for Bateman; a battle which he never seems to be able to ascend. This consistent thread throughout the narrative, of fact versus fantasy, also serves to replicate the 'doubling' aspect of the Gothic 'other' as it relates to the psychological state (typically portrayed in fictional accounts of 'maniacs' and 'psychos') of a crazed killer with a 
'split personality. ${ }^{21}$ Other similar fictional examples of this type of characterisation can be found in works such as Robert L Stevenson's Strange Case of Dr. Jekyll and Mr. Hyde and Robert Bloch's Psycho.

Some critics have identified this ambiguous duality of character, as being representative, of more than a mere literary trope and somehow evidence of a thinly disguised autobiography sans narrative of the author's own perverse fantasies. For example, Justine Ettler intimates that “. . the novel's excessive ambiguity leaves the reader no choice other than to resort to their biographical knowledge of the author in order to make sense of it . . . in relation to Ellis's biography, as well as in relation to Ellis's recent revelations about his sexuality and his interview practice"(4). In his book The Poetic Mind, Frederick Prescott suggests a Freudian interpretation of the author's relationship with their leading characters, in that "the fictional character corresponding to the author is always a sort of dream-figure, in which the author's person is modified by a composition, in a way answering to the author's desires," and further "...in the bad characters the author will be harder to identify, because they represent him with a concealment or "displacement" due to repression ... there is an identification or composition, in which the main ingredient is the author himself, but with an ingredient also of externally derived features" (193-201).

Bateman's fractured personality reflects the postmodern nature of his character and extends to the novel's preoccupation with surfaces. This prevailing surface motif extends to his own knowledge of serial murder, much as it would to most members of the general (American) public in that this type of knowledge is usually sourced from fictional and tabloid representations. This mimetic quality of Bateman's, to imitate and reflect the cultural knowledge of his peers is evident in the way he emulates characters and scenes from pop-culture. He talks about Ted Bundy, the most infamous real American serial killer; he discusses the film 'The Texas Chainsaw Massacre' and scenes from 'Body Double' in casual conversation. However, these actions seem to reinforce the shallowness and unreliability of his character rather than providing any true significance behind his shallow preoccupations and interests. Factual case

21. The 'split personality' is a common trope associated with depictions of fictional human evil, usually associated with outdated psychiatric terminology related to mental-health patients who display violent tendencies and are afflicted with Schizophrenia. The term 'split personality' is now considered defunct, although still used as a popular term for different types of mental illness, and has been replaced by the term Dissociative Identity Disorder, applicable to those who suffer from a psychiatric condition once known as Multiple Personality Disorder. Retrieved from: https://en.wikipedia.org/wiki/Dissociative_identity_disorder 
studies of serial killers show that they typically carry out their crimes repeatedly with a modus operandi, or method of operation, known as their 'signature.' Other works of serial killer fiction, up until the publication of American Psycho, have consistently used this knowledge of factual serial homicide practices to accentuate the validity and realism of their respective stories and characters. Ellis, however, uses the many types of violence much as he does with the 'lists' that are scattered through the novel. The descriptions become lists of atrocities, similar to the descriptive lists of consumer goods and pop-culture iconography throughout the novel, rather than an accurate portrayal of a realistic serial killer at work. In this case, the killer endeavours to be as various with his methods as he can be with each victim, each murder seemingly more horrific and outlandish than the ones before. This move away from the factualness of serial killer etymology, signals that the narrative cannot be read like other works of serial killer fiction that typically emphasize realism and accuracy in accordance with examples of factual crimes.

Bateman's identity crisis is grounded in the dichotomous nature of the archetypal serial killer character that relies on Gothic ontology as a means to define and separate the serial murderer from apparently 'normal' citizens. This tradition of labelling and associating human aberrant behaviour with the monstrous has been relied on for centuries to disassociate the outsider from the general populace, especially so in narrative works (both factual and fictional). Perhaps the greatest example of this can be found in Gothic literature where human criminality is presented as evil, for example: Robert Louis Stevenson's Doctor Jekyll and Mister Hyde, Mary Shelley's Frankenstein, Bram Stoker's Dracula, Thomas Harris's Silence of the Lambs and Ellis's American Psycho. The battle between good and evil is embodied in the character's repression of his or her primal desires, usually presenting itself as a split persona, or a changeling-type entity that often borders on the supernatural in the rhetorical language used to describe the depths of depravity. The language used to describe these characters employs rhetoric designed to emphasize, not only the monstrous qualities of their personas and behaviours, but their difference from average human beings who do not engage in criminally violent behaviours. Literature dealing with serial murder commonly uses these tropes across all genres and may well be inescapable, especially when dealing with the less-than-common human proclivity for violence and deviance.

Bateman's identity crisis is equally governed by the traditional rhetoric of Gothic literary tropes and tradition utilized by both fictional and factual antecedent works, as it is by the 
epistemological influence of Ellis in that his (Bateman's) character's portrayal of itself as a quintessential American Psycho is tempered by the author's own understanding of what constitutes a serial killer. The use of gratuitous and hyperbolic violence to emphasize the 'monstrous' nature of the character, is an attempt by the author to enhance the legitimacy of the character as a true psychopathic killer over-and-above any aesthetic concerns possibly intended by its usage. Ellis reinforces these displays of the monstrous by transcribing Bateman's thoughts in a verbatim style, more academic in nature than stream-of-consciousness. This mode of description once again serves to validate Bateman's role as serial killer (lest there is any doubt), but also reveals Ellis's own understanding of the subject matter which he cleverly negates by undermining his thoughts at the conclusion of his monologue:

... there is an idea of a Patrick Bateman, some kind of abstraction, but there is no real me, only an entity, something illusory, and though I can hide my cold gaze and you can shake my hand and feel flesh gripping yours and maybe you can even sense our lifestyles are probably comparable: I simply am not there. It is hard for me to make sense on any given level. My self is fabricated, an aberration. I am a non-contingent human being. My personality is sketchy and unformed, my heartlessness goes deep and is persistent. (376-7)

In summation, the title of Ellis's novel distinguishes American Psycho as being an American novel as well as a character-study of what constitutes a rather exaggerated American psychopath. Patrick Bateman is the epitome of the 'American dream' - rich, successful, white, outwardly conservative, confident and aesthetically handsome. To the point that he is almost a super-hero in his physical stature and double-identity - even his name alludes to 'Batman,' the alter-ego of Bruce Wayne, the multi-millionaire playboy whose violence is brutal and whose character is dark and mysterious in the guise of a bat (incidentally, a traditional symbol of Gothic horror). This juxtaposition of American pop-culture mythos, Gothic tradition and period sociopolitical concerns, combined with Ellis's tongue-in-cheek satirical exposition of idealised American values, struck a chord with readers and critics who were polarized by the novel. Not surprisingly, the controversy was not sparked by the less-than-subtle transgressive breakdown of the American dream, but by the scenes of violence and abhorrent sexual behaviours within the narrative.

Seemingly, the descriptions of violent sexual crime were the main critical targets within the novel, resounding with a critical and public audience who had been fed a steady diet of 
similar gratuitous media representations since World War One. The fact that these scenes were integrated into the narrative next to descriptions of American pop-culture phenomena such as popular music, film and media references, effectively insinuates that serial murder is as 'American as apple pie.' The surface levels that Bateman constantly refers to throughout the novel, paradoxically become as much a part of the critical responses that focus only on the graphic descriptions of violence and sex, as they are integral to the overarching postmodern qualities of the narrative. In this respect it is a narrative concerning surfaces, which in turn invites a superficial response to face values, rather than to the more complex and serious underpinnings of the work as serial killer fiction.

Ironically, because of this typical type of critical reaction, the serial killer novel assumes a status much like the serial killer itself - publically feared, demonised, mythologized, and the object of socio-political criticism and manipulation. In this regard, the fictional serial killer becomes an allegorical focus-point, or scapegoat, for those with agendas who wish to apply subjective theory and politically-motivated attacks in order to further their respective mandates. This observation is not a defense of the serial killer (factual or fictional), nor is it a rebuttal of those differing critiques, however it does show that many of the critical perspectives are tempered by less-than-objective grounds. Indeed, the use of a figure to symbolically allocate blame and fear for society's foibles and political mandates is nothing new. Most cultures have their own versions of what has commonly been referred to in the past as the 'Bogeyman.' The contemporary version of this phenomenon is the terrorist who has now overtaken the serial killer in American society as the main threat to the American 'way of life.' The serial killer has now been reduced to a secondary tabloid source of scandal since the 9/11 bombings of the World Trade Centres in New York. The mega-violence of suicide-bombings and the 'otherness' of the terrorist has made terrorism a much more marketable foil for media sales (television, print, enews etc.) and political posturing.

What had been a distinctively American problem with serial homicide, because of the amount of interest generated by the media and the public's fearful response, had now been subsumed by the terrorist who had none of the predilections and kinky quirks that fascinated American citizens for decades. In this respect, the terrorist is a 'cleaner' version of the serial killer and much more palatable, as an ultimate bogeyman figure for an increasingly conservative American society, with none of the lurid sexual aberrations or deviant behaviours that are 
inextricably linked to serial homicide and which fuelled the public's imagination by way of pulp detective magazines, tabloid newspapers and ghoulish television documentaries up until 9/11. The problem with the serial killer and one of the main reasons why he appears to have been derailed by the terrorist as the ultimate American bogeyman, is that he seemed to be representative of the society from which he originated. This problematic aspect of serial killer fiction (i.e. the serial killer character is too familiar) is also the source of most criticism levelled at American Psycho; the violence and misogyny in my view merely bolster this perception. By most accounts and as Steven Egger suggests, serial murderers:

... do not look like killers, nor does their appearance reflect an ultimate evil. Unfortunately, serial killers simply do not stand out on our city streets, in suburban neighbourhoods, or on our highways, as anything other than the average person ... Without a criminal identity, however, in most instances the serial killer looks like everyone else ... Even though a number of people retrospectively reinterpret the background and appearance of a serial killer after he or she has been caught, many others marvel at the fact that these killers look like the "boy next door," just your "average Joe," or "just like any other normal person" ... The normal outward appearance of the serial killer seems to dumbfound many people and remains a fascination for many more. (The Killers Among Us, 47)

The fact that serial killers are outwardly normal in appearance and can potentially originate from any corner of society, created a huge groundswell of fear and fascination in the latter half of the Twentieth century and it is plain to see why. During this period, despite serial murder being a global phenomenon, the United States were reported as having the greater percentage of serial killers (usually male) per head of population by a variety of sources. The reality was much different, however, with "mass, spree, and serial murders combined represent[ing] at most 2 percent of all American homicides." (46) This prevalence of exaggerated reporting had the effect of increasing public fear and apprehension about perceived crimes of serial murder to the point where unsolved homicides were often cited as evidence of the prevalence of serial killers in society. It was in this atmosphere of public and media hysteria that Ellis wrote American Psycho and, because of the great interest in the subject matter, it was possibly a central reason why he wrote the novel, knowing full well that it would generate controversy and, ultimately, book sales. 


\section{CHAPTER FOUR: CONCLUSION -}

\section{A Working Definition of Literary Serial Killer Fiction}

"What has generally been neglected, however, is a comprehensive attempt to study multiple murder as an impetus for myth - and narrative-making, particularly in contemporary America where the metaphoric legacy of frontier violence lingers on."

- Philip Simpson

This thesis has proposed that within the larger framework of narrative fiction representing serial killers, there is a group of texts that have a set of distinctive features that distinguish these works as a particular form of serial killer fiction. It has been the contention of this thesis that these select works are distinct enough from other genres, and share enough commonalities, that they comprise a genre category of their own that can be classified as literary serial killer fiction. The specific works I examine in this thesis belonging to this category are: Jim Thompson's The Killer Inside Me, James Ellroy's Killer On The Road, and Bret Easton Ellis's American Psycho. The defining features that classify these works as members of this literary genre, are as follows. 
Literary serial killer fiction is a narrative work of the imagination, narrated in first-person perspective from the point-of-view of the serial killer, who is also the lead protagonist. In literary serial killer fiction, the protagonist is always the serial killer, as opposed to the more traditional role of the detective or investigator featured in crime/mystery novels and the more general subgenre of serial killer fiction. The antagonist is usually portrayed as the investigator who is attempting to capture the killer and there is no apparent plot to most literary serial killer fiction narratives, other than there is a killer who murders victims and who may or may not be caught. Another characteristic of this category is a distinctive thematic concern with the psychopathology of the killer and, occasionally, the effect of violence perpetrated on the victim/s. This thematic idiosyncrasy extends to the rendering of the psychological state of the killer and his viewpoint usually by way of the narrative mode of stream-of-consciousness. Most well-crafted examples of literary serial killer fiction (and serial killer fiction) show an epistemological understanding of and recourse to contemporary legal jargon used in describing psychological states, criminal law and terminologies related to law enforcement procedure. Knowledge of historical antecedents in terms of criminal case-studies and events are also commonly evident, with many authors modelling fictional serial killer characters on factual murderers or composite characterisations of real-world criminal profiles. While being a distinctive offshoot of the more formulaic serial killer fiction sub-genre of crime fiction, literary serial killer fiction can also be found within other genres. For example, Bret Easton Ellis's American Psycho is classified as a work of transgressive literary fiction as is Joyce Carol Oates's, Zombie (not discussed here in this essay); both of these works sit under the mantle of the overarching literary fiction genre.

Within the selected examples of literary serial killer fiction discussed in this essay, the criterion listed above (especially the thematic concerns with violence, psychological interior worlds and the horror of the serial killer's crimes), take precedence over traditional literary devices used in examples of crime fiction. Another defining feature of both serial killer fiction and literary serial killer fiction is the invariable recourse to true-crime narratives, evident in the tabloid-style descriptions and terminology used to depict violent crimes and psychological profiles of serial killers. Narratives such as The Killer Inside Me, Killer on the Road, American Psycho and Zombie are shown to invert literary conventions and offer a transgressive alternative to traditional crime fiction (and its sub-genres) where the focus and perspective of the narrative 
stems from the psychological interior of the villain protagonist. Any characterization of law enforcement or investigative procedure is typically of secondary value to the narrative, if included at all, and the investigator or pursuer of the criminal lead, is usually portrayed as the antagonist.

I chose the three works in question primarily because they meet criteria indicative of literary serial killer fiction as a genre in its own right. Other narratives deemed of note that use the tropes of serial killer fiction were not included because they essentially remained firmly entrenched within the genre conventions in which they were written. That is, they could not be classified as literary serial killer fiction because they still employed conventions and tropes common to other genres. For example, works such as Thomas Harris's Red Dragon and Silence of the Lambs, regarded by many critics as pinnacles of the serial killer 'formula' within genre fiction, do not necessarily meet the necessary and sufficient conditions to be classified under literary serial killer fiction alone. Mainly because of their status as psychological thrillers and conformance to formulaic genre conventions within the larger overarching genre of crime fiction including the subgenre of serial killer fiction, these narratives clearly follow in the tradition of detective fiction (a genre category of crime fiction) where the protagonist is the investigator and the antagonist is the criminal perpetrator. Usually, in serial killer fiction that sits under overarching genres such as crime fiction, the narrative point of view is from the perspective of the protagonist who is a 'good' character, as opposed to the antagonist who is always a villain. More emphasis is placed on the pursuit and capture of the criminal in these narratives with clearly defined plots and thematic tropes familiar to canonical traditions.

As mentioned above, the works I have discussed are all first-person narratives written from the perspective of the serial killer protagonist, which in my opinion is the main defining criterion of serial killer fiction (as opposed to narratives that use serial killers as plot devices and character studies under the rubric of other genre categories and first-person narratives that aren't told from the perspective of the serial killer). Narratives such as Robert Bloch's Psycho and Thomas Harris's Silence of The Lambs, while containing elements focusing on the psychological aspects of a psychopathic killer, are essentially suspense novels as they concentrate on the 'who' rather than the 'why' of which literary serial killer fiction is primarily concerned. Obviously, narratives that do meet the criteria of being stylistically, thematically and rhetorically identifiable as literary serial killer fiction, owe a huge debt to earlier works such as Stevenson's The Strange 
Case of Dr Jekyll and Mister Hyde (1886), Marie Belloc Lowndes', The Lodger (1913), Davis Grubb's Night of the Hunter (1953), and, of course, Robert Bloch's Psycho (1959). This is by no means an exhaustive list, or one that traces the origins of general works of serial killer fiction in terms of non-fictional antecedent works. I have shown in this thesis that fictional representations of the serial killer are in most cases directly influenced by antecedent factual and fictional narratives entrenched in historical events.

As outlined in this discussion, the critical response to many of these works is usually politically and socially motivated in response to the violence and victimology perpetuated by these narratives. Obviously, works that primarily involve the violent murder of women are open to feminist critique and lend themselves to a literal reading of misogynistic plot lines and character attributes. Applying a feminist critique to all works of serial killer fiction is problematic, mainly because there are a growing body of texts available that are written by women from the viewpoint of a female protagonist who both apprehends and, occasionally, murders male victims. Works like Patricia Cornwall's 'Scarpetta' series are driven by a strong female lead who battles male misogyny, both in the workplace and by the predominantly male murderers she deals with. In her novel Exquisite Corpse, Poppy Z. Brite's unique portrayal of male homosexual serial killers also leans towards a feminist critique but from a different angle all together. Deciding which type of literary interpretation to utilize in order to understand the work best, will ultimately result in different readings of a single text, depending on which school of theory is applied. Critical responses by feminist theorists (despite political allegiances and gender biases that inform analysis), are no less important because of their subjective leanings as they provide a very important quotient in the growing body of critique concerning the impact of violence on society (particularly against females), and the influence of media depictions on society at large. The prevailing strain of portrayals of violence against women in serial killer fiction and literary serial killer fiction, is an unseemly aspect of the genre/s, but nonetheless a realistic depiction of media and cultural values and something that should be critically appraised for what it represents.

Perhaps the most interesting method of literary interpretation, in regard to American serial killer fiction, is a cultural critique tempered by Marxist precepts. The Marxist 'class struggle' is prevalent across most of the serial killer fiction texts I have studied. The depiction of the character of the serial killer is firmly rooted in a class-conscious profiling in terms of a 
number of common traits and tropes. The fictional serial killer is always presented as an 'outsider' in relation to his/her place in society. On the surface they may at first be presented as a normal 'average' representation of a social (usually middle-class) sect, but as the true nature of the serial killer is revealed to the reader, antecedents such as an impoverished childhood, abuse, a poverty of love and parental role-modelling, if you will, and a status anxiety emphasized by the serial killer's class consciousness and resentment towards society in general is shown. Whether or not these aspects of the serial killer character are intentionally drawn by the respective authors, these subtle commonalities (as examined in this essay) show the relation of the 'self' to the 'other' from the viewpoint of the serial killer. At times these characteristics border on cliché and are informed as much by commonly-held beliefs and social norms as they are by non-fiction accounts of real-life killers. What is interesting is that there is more than an accepted protocol at play here when portraying realistic depictions of serial killers in fictional works.

The common portrayal of the serial killer inadvertently reveals an underlying axis of division present in the basis of their characters. Beneath the main emphases on sex, psychological deviancy and a propensity towards violence as being the primary motivating factors behind the serial killers urge to kill, a more subtle and less-obvious driver can be found. As a reaction to Capitalism, serial murder can be read as both symptomatic of and in opposition to, on a number of interpretive levels. The repetitive and consumptive nature of serial murder aligns the serial killer with consumerist symbolism. In this respect, the serial killer is the ultimate postmodern capitalist consumer: they lust or desire their next victim, they 'consume' the lives of others (sometimes literally via cannibalism. See American Psycho, Zombie etc.), and covet power, greed and success (evading capture and chasing higher body counts). In opposition to Western (class, gender, cultural etc.) values and Capitalist norms, the act of serial murder can be read as a symbolically powerful reaction via the destruction of the 'other' (the atypical member of that society). The victimology of serial killer fiction swings between high and low class representations, mainly represented by gender specific and archetypal examples of class/cultural roles within society. For example, many serial killer victims are portrayed as female prostitutes who are hopeless drug addicts straddling the poverty-line. Other common characterizations include rich, beautiful/handsome and powerful figures who are targeted because of their status and the impact their deaths will make on the media. No matter who the victim, power and domination in relation to class (whether as an attack on or a reaction to) informs the choice of 
victim before consideration is given to the more sensational and oft-emphasized deviant desires of the killer. The 'value' of the victim is ascribed in terms of their place in society; no matter who the serial killer murders, the victim is commodified and objectified to the point where they become 'things' - pure materialist symbols of the culture and society from where they originate.

Along with the cultural ramifications of serial killer fiction, of particular interest to this essay has been the use of figurative language, first-person narration and the influence of outside genre tropes on works classifiable as literary serial killer fiction. Highlighting the prevailing use of these literary devices within select examples of serial killer narratives, this study also shows how authors manipulate and draw from available representations (both factual and fictional) in order to produce a certain type of character that is 'hyper-real,' in the mythogenic sense that the serial killer is commonly represented as a postmodern 'super man.' One of the main considerations of this study has been the implications and ramifications of the portrayal of fictional serial killers in this manner and the reasons behind the continued fascination of the reading public, with this type of fictional sub-genre and character type. The identification of the archetypal fictional serial killer as a measure by which these particular works both reference and seek to differ in their respective constructs, has been examined under the auspices of a new historicism critique in a postmodern context. The conflation of history and literature have hopefully been clearly illustrated in this study of literary serial killer fiction as defining features that allow particular narratives within this category to be situated, in terms of literary and social merits, as a postmodern phenomenon.

The post-war development and growth of American 'serial killer' narratives can best be explained in the context of historical and genre antecedents, with emphasis on the post-modern characteristics of the genre movement and its popularity with the reading public. The genre of serial killer fiction, as a sub-genre of the over-arching crime fiction genre, is seen to be heavily influenced by Gothic narrative convention and the folkloric origins of the horror story. Ever since the invention of the printing press, allegorical stories of pseudo-supernatural beings such as vampires, werewolves, demons and monsters, have been translated from a long line of folkloric oral traditions, where representations of human evil were used to relay religious, social and political agendas in the guise of metaphorical tales of warning.

These parabolic stories representing the darker side of human nature, laid the foundations for the genre fiction of today, especially horror, science fiction, fantasy and serial killer fiction. 
The postmodern depiction of the serial killer figure in fiction, is an amalgamation of these literary and historical traditions. The transgressive figure of the 'Bogeyman,' the symbolic figure of human fear, has found a perfect vessel in the modern serial killer to continue the general public's preoccupation with perceived threats to mortality.

As paradoxical as it may seem, the serial killer portrayed as the 'every man' - the average, ordinary human who hides a dark and deadly secret behind a normal countenance - is the ultimate unknown but known quantity. He (usually male) could be your father, brother, uncle, et cetera and it is precisely because of this benign anonymity that makes him such a terrifying embodiment of human fear; fear of the unknown, of death, but also the troubling representation of the potential evil in all human beings. While serving as an analogous construct, this fictional mystification of the ordinarily banal figure of the serial killer is also part of a larger glorification process that creates anti-heroes out of villains. As Steven Egger suggests in his study of serial murder, The Killers Among Us:

The United States has long made legends out of outlaws. American history is full of the folklore of killers, many of the so-called heroes of yesteryear, including the lawmen and gunslingers of the old West, would fit the modern definition of serial killer. The legends of Wyatt Earp, Billy the Kid and Butch Cassidy and the Sundance kid all contribute to this mystique. One of the key elements of the personality of the serial killer appears to be that he kills for an intrinsic motive, simply, he enjoys killing. Many of the "heroes" of the West displayed this trait. All forms of the media have contributed to this portrayal of serial killers as clever, daring, sexy, and elusive. (103)

Indeed, the serial killer figure in both fact and fiction is permeated with this symbolic appeal (especially to American audiences) because of the confabulation of all these elements. The relationships are inextricably connected in the cannibalizing of each other, as various genre conceits and media agencies continue to further the mythogenic properties of what has become a rhetorically malleable narrative trope. Given these aspects of the genre of serial killer fiction and the portrayal and interconnectedness of the figure of the factual serial killer, as constructed by generalized media and agency (FBI) reporting, it has been the purpose of this study to analyse the phenomena as it functions in selected American post-war narratives up until the millennium.

Another finding of my research is that the most influential antecedent on the fictional serial killer is the horror genre. The transgressive nature of the horror genre has expanded what was once a primarily Gothic literature based in folklore and religious concepts about evil and the 
supernatural, into an all-encompassing milieu that incorporates hard-to-define schools of style and theme such as paranormal romance, splatterpunk, weird, urban fantasy, apocalyptic, dystopian and serial killer fiction to name a few. Critics have noted this debt of lineage by pointing to the use of common themes and tropes that link each genre and the effect they have on an audience. In A Dark Knights Dreaming: Contemporary American Horror Fiction, Michael Morrison suggests that:

The theme of victimization also empowers the . . . late-twentieth-century horror archetype the serial killer ... the serial killer is primarily urban (an embodiment of the fear of random violence that now defines city life) ... [and] typifies perhaps the most significant thematic shift in modern Gothic ... The serial killer tends to slash his way through the surface of narrative - vivifying in text rather that subtext the fears of the culture. The serial killer novel brings to the surface the pervasive paranoia that underpins most modern horror, where we are all potential victims trapped in inherently uncontrollable natural or technological environments, within a cosmos that is at best indifferent, most such works display an appalling atrophy of the imagination. Their authors seem to operate on the assumption that the mere mention of a psychopath or serial killer, accompanied by graphic renderings of diverse atrocities, suffices to make a successful horror novel. Lacking either subtext or subtlety, these novels amount to the literary equivalent of Friday the Thirteenth movies.

While serial killer fiction is firmly rooted in the horror genre with its prevailing tropes and themes of death, evil and terror, it still manages to straddle the genre boundaries as a significant player in the crime fiction genre. The point of intersection is in the American pulp magazines produced around the time of the First World War, where detective stories sat alongside tales of horror and the fantastic. Serial killer fiction is of itself transgressive in that the only criteria a fictional work needs to meet to be included in this subgenre is that either the protagonist or antagonist must be depicted as a serial killer. The conclusion of this study places the selected works (of serial killer fiction) as more significantly informed by the horror genre, due to the overarching and common effect of the works in question. As J.A. Cuddone points out in A Dictionary of Literary Terms and Literary Theory:

Often horror stories are noteworthy for their exploration of the limits of what people are capable of experiencing. They venture into the realms of psychological chaos, trauma and taboo desire, and the near side of barbarism; they explore the capacity to experience fear and what lurks on and beyond the shifting frontiers of consciousness. The horror story is part of a long process by which people have tried to come to terms with and find adequate 
descriptions and symbols for deeply rooted and powerful energies and fears which are related to sexuality and the body, death, afterlife, punishment, darkness and violence. (340)

Unlike the majority of crime fiction, serial killer fiction solicits a response akin to that of horror fiction, in that it is comprised of a "fictional narrative (usually in prose) of variable length which shocks [that] even frightens the reader, and/or induces a feeling of repulsion and loathing" (339). This apt description could well serve as a definition of the characteristic modal aspects of serial killer fiction and extends to the mythologizing tendency that characterises portrayals of the serial killer as a postmodern embodiment of cultural fear. Another name for this type of allegorical representation is the 'bogeyman,' which has its own set of distinct characteristics much like the serial killer along with some interesting parallels. Aside from the literal nature of a person who murders multiple people and the subsequent term of 'serial killer,' the serial killer in narrative form is imbued with symbolic meaning and application much like the bogeyman. Fear is the essential characteristic of both allegorical figures as is the potential to consume (literally and figuratively in the case of serial killers) or threaten life. In Marina Warner's expose titled No Go The Bogey Man, she states that:

... appetite defines bogeys, and many myths explore obsessively a deep and insistent fear: that the thing in the dark wants to gobble you up. Much of this lurid cannibalistic material acts as metaphorical disguise ... it relates ways of confronting the foundations of the sense of identity and the self and of the self's historical and social place ... Bogey figures sometimes tear their victims limb from limb in their raw state, devouring them alive - or as carrion ... All of them death portents, they often specifically pursue children . . . Monsters, ogres, and beasts who kill and eat human flesh dramatize the complexity of the issue: they variously represent abominations against society, civilization and family, yet are vehicles for expressing ideas of proper behaviour and due order. (10-12)

As can be seen from the excerpt above and by the examples provide throughout this thesis, the bogeyman figure draws remarkable parallels with the serial killer in the way both figures are manipulated, to instil fear and inforce ethical judgements in relation to what is considered right and wrong. Obviously, the bogeyman is a purely allegorical figure who has no tangible existence other than the fear it imparts and the (factual) serial killer is a more human embodiment of fear and threat. Other critics such as Joseph Grixti, extend this association of the serial killer as a contemporary bogey-man figure, by analysing the apparent American obsession with violence and serial murderers. In his essay, Consuming Cannibals: Psychopathic Killers as 
Archetypes and Cultural Icons, Grixti outlines the process of myth-making and fictional transcription which accompanies the increased public awareness of serial killers and their crimes:

Fictionalizing figures like... [Ted] Bundy as inhuman monsters is one way of coming to terms with the dislocations that they generate in order to preserve the preferred contours of our own identity. Popular fiction, because of its very generic and formulaic nature, frequently acts as a frame of reassurance which allows us to safely engage in this exploratory process. The process involves locating the criminal-outsiders within a tradition, and identifying their affinities with antecedents - which have in their turn been made part of a mythology. What we and our cultures are engaged in when we endeavor to contextualize serial murderers within this broader mythology is an exercise designed to allow them to be habitually perceived in the same unthreatening terms as is the case with domesticated mythic monsters like the werewolf or the vampire. (90)

As suggested above, the basis for most representations of the serial killer character as an allegorical literary device, is mainly due to the relevance and potency of the figure to American cultural concerns. Critics, such as Philip Simpson, have pointed this out as a specific methodology employed by both fictional authors and 'factual' media reportage:

Serial killers in particular direct attention away from the social milieu in which they flourish and onto intriguing but ultimately fruitless psychoanalytic explications of their supposed lunacy. This is where the best of the serial-killer fiction I have examined can function as a corrective in a way that the lurid media coverage of actual murderers usually does not: a method of refocusing on the context and not the isolated singularity.

(Blurring All Boundaries, 214)

In summary, this thesis has explored the history of American fictional works that make up the loosely defined literary sub-genre of serial killer fiction and, more particularly, literary serial killer fiction. It has been the intention of this essay to clearly define what constitutes 'literary serial killer fiction' and to chart the development and evolution of narratives that can be classified as serial killer fiction. With recourse to select examples and the most relevant critical texts, I have discovered that serial killer fiction is an influential sub-genre present in many established fiction genres, such as crime, detective, thriller, suspense, and horror. This pool of genre antecedents is also the locus of the development of literary serial killer fiction, which I argue can be classified as a subgenre of serial killer fiction and literary fiction. The phenomenon of serial killer fiction has proved interesting, not only because of the complex nature of the 
works in question, but also because of the many sociocultural issues that are invariably raised when these narratives are scrutinised. Oftentimes, both critic and reader alike are left with more questions, about the popularity of the genre and what constitutes a true and valid fictional rendering of a serial killer, than answers.

The appeal of the serial killer, in fictional and factual representations, points to a greater preoccupation with allegorical figures who represent the greatest threat to 'everyday' people. Gothic antecedents in folklore and mythology, combined with historical evidence of the human predilection to create monsters that embody fear and moral underpinnings, show that the figure of the serial killer is not only a modern phenomenon but one that can trace its lineage as an allegorical 'bogeyman' back through human history. It is precisely this combination of historical and fictional aspects that determine the unique nature of serial killer fiction and its emergence as a hybrid literary genre.

An interesting finding of this research is that while serial murder is celebrated and obsessively recreated in works of fiction, the act of mass murder does not seem to hold the same appeal or status. These two types of multiple murder are not that much different in terms of victimology and the effect of the crime, but yet in terms of their aesthetic appeal as works of fiction/art the serial killer is the clear favourite. The obvious appeal to creators of serial killer fiction is in the seriality of the trope. The repetitive nature of the serial killer's crimes lends itself well to a continual chapter narrative and to established thriller/mystery plot lines that involve criminal acts, followed by procedural deduction and eventual resolution. The serial nature of the crimes and the main characteristics of the antagonist's actions and personality (or protagonist depending on type of narration), ensure that many of these types of works are serial novels, that is one of many in a series. The expression of cunning, intelligence, human evil and 'genius' all find a home in the serial killer character, but not so in the figure of the mass murderer who seems to operate on a more base level indicative of someone who has no self-control, will-power or aesthetic sensibility. The act of the singular crime of multiple/mass murder as one event, as horrible as it may be, is the epitome of the 'loser' who is ultimately suicidal and beyond any finesse or variation. This individual human anomaly is perhaps one of the most intriguing to readers and to the public because of the serial nature of the crimes.

Much like the popularity of soap operas and long running television sitcoms, serial murder proves an alluring form of repetition especially when combined with the moribund fears 
of a society who are primed by tabloid media with regular sensationalised accounts of graphic violence and murder. The truth is far from what is presented to the public by media agencies whose main objective is to sell subscriptions. According to recent FBI crime statistics, ${ }^{22}$ serial murders in the United States of America account for only one percent of all homicides within the U.S. per annum. With an approximation of 15,000 homicides per year annually, only 150 of those murders are committed by serial killers. Most FBI statements estimate the amount of active serial killers (i.e. those 'on-the-loose') operating in the U.S., to average between twenty-five and fifty depending on kill ratios per perpetrator. Despite this evidence that serial murder is a relatively rare phenomenon, politicized media reporting and pop-culture representations have perpetuated myths about the threat of serial murder within American society and, consequently, have generated the necessary conditions for serial killer fiction to take root as a genre in its own right.

Despite the reading public's fascination with the idea of the serial killer, the representations are not necessarily 'true' or accurate in most fictional portrayals of serial killers. Indeed, the fictional representations are usually hyperbolic and a fair amount of poetic license is typically employed to exaggerate the protagonists' villainous characteristics, more in line with established fictional representations of monsters and mythological figures such as 'The Bogeyman.' By showing how the authors employ these techniques and devices, this essay exposits how they cater, in a fictional and cultural sense, to certain aspects of the public's fascination with real-life crimes and characters and how they extend the motif of the serial killer as a genre archetype. This aspect of serial killer fiction emphasizes its viability as a genre in its own right, and the reason why the genre draws the attention of critics who can see the value in the thematic and cultural power of the narratives.

Most of the critical work regarding serial killer narratives consider the impact of the serial killer in cultural or political terms. For example, in his book Serial Killers: Death and Life In America's Wound Culture, Mark Seltzer argues that various media caters to and perpetuates a prevailing public obsession with serial killing and violent trauma. He calls this preoccupation a 'wound culture,' a (distinctly American) culture captivated by “torn and open bodies and torn

22. Uniform Crime Report. 2011. Retrieved http://www.fbi.gov/about-us/cjis/ucr/crime-in-the-u.s/2011/crime-in-the-u.s.2011/violent-crime/murder 
and opened persons, a collective gathering around shock, trauma, and the wound" (2). In the context of serial killing, Seltzer suggests that the serial killer is "one of the superstars of our wound culture.” In Language, Ideology and Identity in Serial Killer Narratives, Christiana Gregoriou examines non-fiction and fictional narratives detailing serial murder to deconstruct the identity and consciousness of such portrayals as well as how factual and fictional accounts linguistically compare and contrast. The identity and ideology of serial killer portrayals depicted in various contemporary narratives are analysed by Gregoriou, including newspapers, true-crime books, and fictional novels. Her research is focused on exposing how different media understand and depict the criminal mind schematically - particularly that of the serial killer (175-6).

David Schmid's Natural Born Celebrities: Serial Killers in American Culture also analyses the phenomenon within a socio-cultural context. Schmid situates the serial killer as an exemplar of 'fame' and celebrity culture by examining media portrayals of high profile cases such as Ted Bundy and Jeffrey Dahmer and arguing that "the fame of serial killers is absolutely central to understanding the varieties of cultural work they do in contemporary American culture" (4). He also analyses related phenomena such as the popularity of 'investing' in serial killing memorabilia and the "interactions between celebrity criminals, popular culture, and both institutional and individual investors in serial murder" (65). In Using Murder: The Social Construction of Serial Homicide, Philip Jenkins similarly assesses the contexts of the social construction of serial homicide, analysing political, social and rhetorical aspects of the various forms of media that focus on serial murder. He points towards a generational public fear that was influenced by agencies and interest groups who use serial murder statistics and narratives to further their own political agendas via manipulation and the use of hyperbolic rhetoric. Of particular interest to this thesis is Jenkins' analysis of the use of rhetoric in media narratives and the portrayal of the serial killer in popular cultural forms, particularly fictional narratives. Central to my own conclusions relating to the origins and evolution of serial killer fiction as a genre in its own right, is Philip L Simpson's examination of the American public's ongoing fascination with the serial killer in contemporary film and fiction. The conclusions of my own research in tracking the Gothic origins of serial killer fiction, concur with Simpson who also argues that the serial killer is an allegorical construct embodying American sociocultural fears and that the 
literature and legends that have coalesced around uber-criminals answer the human need to personify free-floating fears, aggravated by the perplexing indeterminacy of the postmodern world, into a specific, potentially confinable, yet still ultimately evil, threat. The marauding serial killers of the late 1970s, 1980s and 1990s encode, deliberately or otherwise, many of our cultural phobias in their polysemous narrative representation[s] in fiction and film. (Psycho Paths, 2)

In conclusion, the genre of serial killer fiction, as a subgenre of the over-arching crime fiction genre, owes a huge debt to Gothic narrative convention and the folkloric origins of the horror story. The Gothic concept of the monster or bogeyman as allegorical representation of human evil and the producer of unconstrained fear, combined with a self-reflexive preoccupation with inner psychological states and society's intolerance of the 'other' in the form of the outsider figure, informs both fictional and factual post-war narrative accounts of serial murder. I have argued in this essay that narratives which meet the criteria to be included in the sub-genre of literary serial killer fiction, also present multiple avenues of investigation and interpretation in terms of literary and socio-cultural critique and analysis. The appeal of the genre to those authors who usually write outside of it, particularly in regard to its transgressive and allegorical qualities, has also been of particular interest to this study. Because of these qualities and the ease with which the central character of the serial killer transcends genres, the sub-genre provides a transgressive outlet for authors who wish to test boundaries (in both a literary and ontological sense), in regard to the commentary serial killer fiction allows on the state of contemporary American literature and society Thus, no matter how 'literary' the narrative, the essential function of the fictional serial killer to embody evil leads me to conclude that it is an ideal form to interact with popular cultural narratives, while also allowing subversive interplay between both real and fictional concerns. 


\section{Works Cited}

Achenbach, Joel (1991, April 14). "Serial Killers: Shattering the Myth." Washington Post. Retrieved from: https://www.washingtonpost.com/archive/lifestyle/1991/04/14/serial-killersshattering-the-myth/b7c60c59-f5f8-4888-98bd-961ca2c3783d/?utm_term=.bcb4a682ba35

Bonn, Scott. Why We Love Serial Killers: The Curious Appeal of the World's Most Savage Murderers. New York: Skyhorse Publishing, 2014. Print

Burke, Edmund. The Works of the Right Honourable Edmund Burke, Vol. I. Project Gutenberg. Retrieved from: http://www.gutenberg.org/files/15043/15043-h/15043-h.htm

Buss, David M. The Murderer Next Door: Why The Mind Is Designed to Kill. London, Penguin, 2006.

Caputi, Jane. The Age of Sex Crime. Bowling Green: Bowling Green State U Popular P, 1987. Print.

- Caputi, J. (1993). 'American Psychos: The Serial Killer in Contemporary Fiction.' Journal of American Culture, Vol. 16 Issue 4, p103-4.

Cuddon, J. A. (John Anthony). A Dictionary of Literary Terms and Literary Theory. 5th ed. Wiley-Blackwell: West Sussex, 2013.

D'Cruz, Glenn. 'Representing the serial killer: 'postmodern' pedagogy in performance studies.' Southern Review: Communication, Politics \& Culture. Vol. 27, No. 3, Sept 1994: 323-332.

Douglas, John E., Olshaker. Mindhunter: Inside the FBI's Elite Serial Crime Unit. New York: Scribner. 1995.

Egger, Steven A. The Killers Among Us: An Examination of Serial Murder and Its Investigation. Upper Saddle River, NJ: Prentice Hall, 1998.

Ellis, Brett Easton. American Psycho. Vintage; 1st edition, 1991.

Ellroy, James. Killer on the Road. William Morrow Paperbacks; Reprint edition, 1999.

Ettler, Justine. The Best Ellis for Business: A Re-Examination of the Mass Media Feminist Critique of American Psycho. (PhD diss.) The University of Sydney. (2012) Retrieved from: http://hdl.handle.net/2123/10020

Goulian, Jon-Jon (interviewer). 'Bret Easton Ellis, The Art of Fiction No. 216.' The Paris Review. Issue 200, Spring, 2012. Retrieved from: 
https://www.theparisreview.org/interviews/6127/bret-easton-ellis-the-art-of-fiction-no-216-breteaston-ellis

Gregoriou, Christiana. Language, Ideology, and Identity in Serial Killer Narratives. New York: Routledge, 2011.

Grixti, Joseph. 'Consuming Cannibals: Psychopathic Killers as Archetypes and Cultural Icons.' Journal of American Culture. V 181: Spring, 1995. 87-96.

Horsley, Lee, Rzepka, Charles J. (Eds.). A Companion to Crime Fiction. West Sussex: WileyBlackwell, 2010.

Jameson, Fredric, Postmodernism, or the Cultural Logic of Late Capitalism. Durham, NC: Duke University Press, 1991.

Jenkins, Philip. Using Murder: The Social Construction of Serial Homicide. New Brunswick, NJ: Aldine Transaction, 1994. Print.

Jones, Richard Glyn (Ed.). Lambs to the Slaughter: Serial Killers and Their Victims. London: Xanadu, 1992.

MacDonald, Alzena (Ed.). Murders and Acquisitions: Representations of the Serial Killer in Popular Culture. New York: Bloomsbury Academic, 2013. Print

Magistrale, Tony and Morrison, Michael A. (Eds.). A Dark Night's Dreaming: Contemporary American Horror Fiction. Columbia: University of South Carolina Press, 1996.

Mailer, Norman. 'The White Negro (Superficial Reflections on the Hipster).' Dissent 4 (1957): 276-93.

Morton, R. J. \& Hilts, M. A.. Serial Murder: Multi-Disciplinary Perspectives for Investigators. US Department of Justice: Federal Bureau of Investigation, 2008. Online version: https://www.fbi.gov/stats-services/publications/serial-murder/serial-murder-1\#two

Murphet, Julian. Bret Easton Ellis's American Psycho: A Reader's Guide. London and New York: Continuum, 2002.

Newton, Michael. The Encyclopedia of Serial Killers $2^{\text {nd }}$ Edition. New York: Facts on File, 2000 .

Oates, Joyce Carol. Zombie. Penguin; Reprint Edition, 1996.

- Oates, Joyce Carol. (24 March, 1994). 'I Had No Other Thrill or Happiness,' The New York Review of Books. 52-59.

Polito, Robert. Savage Art: A Biography of Jim Thompson. New York: Alfred A. Knopf, 1995. 
Powell, Stephen (Ed.). Conversations With James Ellroy. Jackson: University Press of Mississippi, 2012.

- Powell, Steven. James Ellroy: Demon Dog of Crime Fiction. UK: Palgrave Macmillan, 2016.

Prescott, Frederick. The Poetic Mind. New York: Macmillan, 1922.

Ramsland, Katherine. (Oct. 11, 2014.) 'Who Coined “Serial Killer”?' Psychology Today. Retrieved from: https://www.psychologytoday.com/blog/shadow-boxing/201410/who-coinedserial-killer

Schechter, Harold. 'Prose 'n Cons' [online interview], Mystery Magazine, Spring 2015 http://www.prose-n-cons.com/harold-schechter.html

Schmid, David. Natural Born Celebrities: Serial Killers in American Culture. Chicago: University Of Chicago Press, 2006. Print.

- 'Serial Killing in America After 9/11,' The Journal of American Culture; Mar 2005; 28, 1; Performing Arts Database. Pg 61.

Seltzer, Mark. Serial Killers: Death and Life in America's Wound Culture. New York and London: Routledge, 1998.

Simpson, Philip L.. Psycho Paths: Tracking the Serial Killer Through Contemporary American Film and Fiction. Carbondale, IL: Southern Illinois University Press, 2000. Print.

- Blurring All Boundaries: The Postmodern Narratives of Multiple Murder. (Phd diss.) Southern Illinois University, 1996. Pg. 214.

Thompson, Jim. The Killer Inside Me. Mulholland Books; Reprint edition, August 5, 2014.

Wagner, Margaret S. The Monster of Düsseldorf: The Life and Trial of Peter Kürten. New York: Dutton, 1933.

Warner, Marina. No Go the Bogeyman: Scaring, Lulling, and Making Mock. New York: Vintage, 2000 . 